Portland State University

PDXScholar

1979

\title{
A survey of mental health clients admitted to general hospital emergency rooms
}

Marsha J. Beale

Portland State University

Follow this and additional works at: https://pdxscholar.library.pdx.edu/open_access_etds

Part of the Psychiatric and Mental Health Commons, and the Social Work Commons Let us know how access to this document benefits you.

Recommended Citation

Beale, Marsha J., "A survey of mental health clients admitted to general hospital emergency rooms" (1979). Dissertations and Theses. Paper 2815.

https://doi.org/10.15760/etd.2810

This Thesis is brought to you for free and open access. It has been accepted for inclusion in Dissertations and Theses by an authorized administrator of PDXScholar. Please contact us if we can make this document more accessible: pdxscholar@pdx.edu. 
A SURVEY OF MENTAL HEALTH CIENTS

ADMITTED TO GENERAL HOSPITAL EMERGENCY ROOMS

by

MARSHA J. BEALE

A practicum submitted in partial fulfillment of the requirements for the degree of

MASTER

of

SOCIAI WORK

Portland State University

1979 
APPROVED:

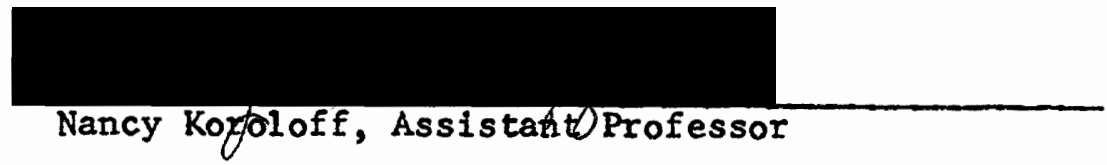




\section{ACKNOWLEDGEMENTS}

I'd like to thank my husband Vince; his patience, understanding, and whole-hearted support have made this all possible.

I'd like to thank Lynn Hingson; she conceived the study, gave me the opportunity to participate, and contributed much more to this report than just her interpretive and writing skills, even though she's not listed as an author.

I'd like to thank Nancy Koroloff; she has contributed to my education by playing many roles, including advisor on this practicum.

I'd like to thank all the people who acted as consultants when I needed advice.

I'd like to thank all the ER staff who took the time to provide the information upon which this study was based. 


\section{PREFACE}

There are three apparent options open to people who are experiencing a mental heal th emergency after normal working hours. The first is to wait until morning (or Monday). The second is to become so severely disturbed that they come to the attention of the police, who may take them into custody. The third option is presenting themselves at a general hospital emergency room.

Two years ago, Mul tnomah County Mental Heal th Division (MOMHD) officials began meeting regularly with community mental heal th service providers to address the third option. During these meetings, service providers indicated that access, availability, and use of emergency mental heal th services were issues of concern for them.

To get more information on the scope of the problem, MCMHD conducted interviews, in May of 1977, with emergency room directors and nurses of eleven general hospitals in the county. The interviews revealed that hospital emergency room staff shared service providers' concerns about emergency mental heal th services. In addition, the emergency room staff indicated that they were seeing more and more people in need of basic mental heal th services but were unable to make appropriate referrals. They cited lack of information about services, 1ack of access to mental heal th services for low-income people, lack of transportation to the referral agency, and various other reasons.

ER $s$ taff and directors agreed that more information was needed in order to plan for improved services, and indicated a willingness to col- 
lect data on mental health ER admissions.

MOMHD decided, on the basis of all the information collected, to approach the Emergency Board with a request to fund a telephone crisis counseling service and a mobile crisis team. In an effort to provide hard data to back up the request to the E-Board, the County Inpatient Services Coordinator, at the request of MCMHD officials, and with the approval of the Emergency. Department Nurses Association (EDNA), began planning a needs assessment survey.

In essence, there were really two target populations: the clients with mental heal th problems who were using the ER, and the ER staff who were dealing with these clients. MCMHD officials wanted information on who these clients were and what their mental heal th problems were. They also wanted information from ER staff about the problems they had dealing with these clients.

It would have been possible to do two separate studies-one on the clients and one on the staff. Instead, MCMHD officials decided to make use of the willingness of ER staff to collect the data by asking them to provide information on the demographic and diagnostic characteristics of clients as well as information on the problems which arose in treating these clients.

Because County officials were only interested in certain admissions--those who appeared to be using the emergency room to solve their mental heal th problems--a true random sample would have been complicated. The ability to predict the size of the target client population, devise a sampling method for hospitals with disparate traffic, and then make projections from the data collected could not be guaranteed. 
The simplest, surest, and least expensive solution to this problem was to take a time sample. In this way, ER staff would only have to make one test to determine whether a client was appropriate for the study-whether he/she was in need of mental heal th treatment. Data would be collected on all appropriate clients during the designated time period. During the time that the methodology and research instrument were being developed, the original purpose behind the needs assessment disappeared. The Emergency Board considered and approved the County's request to fund a telephone crisis counseling service and a mobile crisis team.

It was decided, however, to continue with plans for the assessment, since the data collected could prove useful for planning purposes at a later date. The Coordinator was also interested in determining whether hard data would confirm the more impressionistic data previously gathered. It was at about this time that the writer became involved with the study.

Chapters I through VII comprise the report written for the MOMHD when the study was completed. Chapters VIII and IX were added to fulfill the rëquirements of a practicum. 
TABLE OF CONTENTS

PAGE

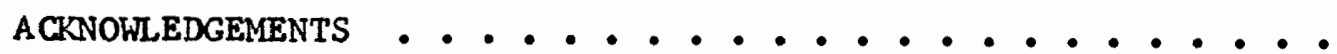

PREFACE .......................

LIST OF TABLES

IIST OF FIGURES ....................

CHAPTER

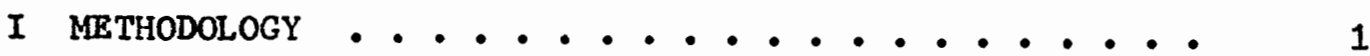

Purpose ................ 1

Instrument ............. 1

Procedures .................. 2

Limitations .............. 3

Organization of Report ......... 4

II MAJOR FINDINGS: INTRODUCTION .......... 5

III MAJOR FINDINGS: WHAT ARE THE CHARACTERISTICS OF

THIS POPULATION?.............. 7

Who Are These Clients? ......... 7

To Which Hospitals Are Clients Going? . . . . 15

When Are These Gients Being Seen? ...... 17

Discussion ............... 20

IV MAJOR FINDINGS: WHAT HAPPENS TO THE CIIENT UPON

ER ADMISSION? ...............

How Long Are Clients Spending in the ER? . . . 23

What Are Clients Receiving in the ER? . . . 25

Discussion ................ 35 
$\nabla$ MAJOR FINDINGS: WHAT BRINGS THESE CLIENTS TO THE

ER?

What is the Presenting Problem? . . . . . 37

What is the Staff Diagnosis ......... 40

Who Referred the Gient to the ER? . . . . . . 42

Discussion .. . . . . . . . . . . 45

VI MAJOR FINDINGS: WHAT ADDITIONAL SERVICES ARE

NEEDED? ................... . . 47

Do Clients Need the Services of Other Agencies? - 47

Do Clients Need Transportation? . . . . . 49

Additional Information ............ 50

Discussion .. . . . . . . . . . . 51

VII MAJOR FINDINGS: REASONABLE vS. QUESTIONABLE USE OF

THE ER ..................... 52

Discussion . . . . . . . . . . . 58

VII IITERATURE REVIEW . . . . . . . . . . . . . 60

Comparison of Findings ............. 63

Who Are These Clients? . . . . . . . . 63

To Which Hospitals Are Clients Going? . . . . 65

When Are These Clients Being Seen? ....... 67

How Long Are Clients Spending in the ER? . . . 68

What Are Clients Receiving in the ER? . . . . 69

What Brings These Clients to the ER? . . . . 72

IX CONCLUSIONS AND RECOMMENDATIONS . . . . . . . . 76

Conclusions ................. 76

Recommendation for Further Study . . . . . . 78 
vili

PAGE

EPILOGUE

81

REFERBNCES

82

APPENDIX

A SURVEY FORH . . . . . . . . . . . . . . . 83

B CATEgORIES USED TO CLASSIFY RESPONSES . . . . . . . 84

C RESPONSES IN WHICH CATEGORIZATION AND INTERPRETATION WERE NECESSARY . . . . . . . . . . . . . . 


\section{LIST OF TABLES}

TABLE

PAGE

I Location of Residences of Clients Studied . . . . . . 8

II Distribution of Survey Population (Mult. Co. Residents)

by Residence Compared to Distribution of Mul tnomah

County General Population by Residence . . . . . 9

III Age Distribution of Gients Studied . . . . . . . 11

IV Distribution of Survey Population (Mult. Co. Residents)

by Age Compared to Distribution of Multnomah County

General Population by Age . . . . . . . . 12

$v$ Distribution of Males and Females Within Population of

Clients Studied . . . . . . . . . . . 14

VI Comparison of Male to Female Proportions in the Survey

Population (Mult. Co. Residents) and in the Multnomah

County General Population . . . . . . . . . . 14

VII Insurance Coverage for Clients Studied . . . . . . . 15

VII Number of Clients Identified as Having Mental Heal th

Problems by Individual Hospitals Reporting . . . . 16

IX Number of Clients Admitted by Day of Week on Which

Admitted . . . . . . . . . . . . 18

$X$ Number of Clients Admitted by Time of Day Admitted . . 19

XI Length of Stay in ER . . . . . . . . . . . . . 24

XII Emergency Room Treatment . . . . . . . . . . 26

XIII Hospitalizations ................... 27 
XIV Referrals .......................

XV $S$ e $x$ of Persons Detained on Notice of Mental

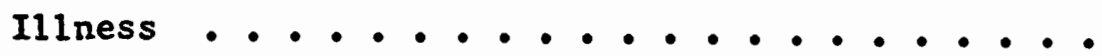

XVI Ages of Clients Detained on Notice of Mental Illness .

XVII Referral Source of Clients Detained on Notice of

Mental Illness ..................

XVIII Day of Week on Which Gients Detained on Notice of

Mental Illness . . . . . . . . . . . .

XIX Time of Day at Which Clients Detained on Notice of

Mental Illness .................

XX Final Disposition of All Clients Studied . . . . .

XXI Presenting Problems ..................

XXII Staff Diagnosis . . . . . . . . . . . .

XXIII Relative Frequencies of Diagnoses as Reported by

Individual Hospitals ..............

XXIV Diagnoses by Sex . . . . . . . . . . . .

XXV Referral Source....................

XXVI Additional Services Needed ..............

XXVII Need for Transportation . . . . . . . . . .

XXVIII Availability of Transportation . . . . . . . . 50

XXIX Transportation Needed But Not Available ........

XXX Comparison of Insurance Coverage: Reasonable vs.

Questionable Usage .................

XXXI Comparison of Additional Services Needed: Reasonable vs. Questionable Usage .............. 55

XXXII Comparison of Age: Reasonable vs. Questionable Usage . 
XXXIII Comparison of Staff Diagnoses: Reasonable vs. Questionable Usage ...............

XXXIV Comparison of Referrals Received: Reasonable vs. Questionable Usage ................

XXXV Comparison of Age Data: Current Study vs. Talley Study . . . . . . . . . . . . . . .

XXXVI Comparison of Number of Males and Females in the Three Studies ..................

XXXVII Number of Clients Receiving Emergency Psychiatric Services . . . . . . . . . . . . . . 66

XXXVIII Number of Clients Seen on Week-Ends and Weekdays . . 67

XXXIX Time of Day Clients Were Admitted . . . . . . 68

XL Length of Stay in the ER . . . . . . . . . . 69

XII Proportion of Study Populations Hospitalized . . . . 70

XIII Types of Agencies to Which Clients Were Referred • . 71

XIII Correlation of Diagnostic Categories Between Studies • 73 XIIV Frequency of Diagnoses . . . . . . . . . 74 


\section{LIST OF FIGURES}

FIGURE

PAGE

1 Comparison of Residences of Mul tnomah County General

Population and Multnomah County portion of Survey

Population . . . . . . . . . . . . 10

2 Distribution of Age in Multnomah County General

Population and Multnomah County Portion of Survey

Population . . . . . . . . . . . . . 13

3 Average Number of Clients Admitted Per 6-Hour Period

by Day of Week . . . . . . . . . . . . 21

4 Final Disposition of All Gients Surveyed . . . . . . 34 


\section{CHAPTER I}

\section{METHODOLOGY}

\section{Purpose}

The purpose of this survey was to obtain information from hospital emergency room staff on each mental heal th admission during the period of December 15, 1977 to January 15, 1978. Mental heal th admissions were broadly defined to include those people who were experiencing an observable mental health difficulty, but who may have initially presented primary medical problems. At the request of Mul tnomah County Mental Heal th Division's Management Team, and with the approval of the Emergency Department Nurses Association (EDNA), questionnaires were distributed among 16 general hospitals in the Portland, Oregon, Tri-County area. These hospitals are located in Mul tnomah, Clackamas, and Washington Counties.

This survey represents the first attempt (1) to obtain information on an area-wide basis, on emergency room (ER) treatment of mental heal th admissions; and (2) to ascertain the availability and use of community mental heal th resources. The collection of such information is important to planning for comprehensive mental health services and in improving the existing service delivery system.

\section{Instrument}

The instrument used in this study consisted of a questionnaire with 18 questions (see APPENDIX A). Recognizing that multiple-choice 
closed questions would limit responses, an open-ended format was developed that would allow ER staff to define the problem from their own perspective.

\section{Procedures}

Questionnaires were given to one representative from each of the 16 hospital ERs in the Tri-County area at an EDNA meeting. ER staff were given the questionnaires by the representatives and asked to complete one on each client admitted to the emergency room who they defined as having a mental heal th problem. They were instructed to include not only clients with observable primary mental health problems, but also clients presenting medical needs with an underlying emotional disturbance.

After the data was collected, responses to specific demographic questions were separated from responses to open-ended questions. The specific demographic data was usable as recorded, but some interpretation and categorization of the open-ended responses was necessary in order to present the information in usable form.

The specific information taken directly from the questionnaire includes:

Number of mental heal th admissions per hospital

Day of the week admitted

Time of admission

Time of discharge (translated into length of stay)

Age

Sex

Insurance coverage

Number of clients hospitalized

Referral source

Need for and availability of transportation

(Data from "Ethnicity" was not used.) 
Responses in which categorization and interpretation were necessary include:

\section{Address of client}

Why did the client come to the ER?

What was identified as the client's primary mental heal th problem?

What treatment did the client receive in the ER?

To what service would the emergency room staff liked to have referred the client?

Were there any unresolved treatment problems or other

Court holds services needed?

(See APPENDIX B for complete list of categories used to classify responses. See APPENDIX C for interpretation of responses to open-ended questions.)

\section{Limitations}

The survey was conducted during a holiday period, and the results may well reflect some seasonal bias. There is no information available to indicate in which direction the bias may exert influence.

A considerable amount of requested information was not supplied by ER staff and the reader is reminded that, in some cases, the missing data, if available, could significantly affect the distribution of the responses. In most cases unrecorded and incomplete information is identified in the presentation of the findings. In a few categories, the number of unanswered questions was small enough to distribute them among the other items in the category based on the total distribution of responses within the category.

The reader is also cautioned that the data was coded and counted by hand and no interrater reliability tests were made. While every precaution was taken to assure accuracy, inaccuracies and small discrep- 
ancies were later found in the data. Since these were indeed small, it was felt that they would not affect the overall picture presented here, and they were allowed to stand.

\section{Organization of Report}

The presentation of the major findings is organized in the following manner, which corresponds to the sequence of questions on the survey form. (The reader may wish to refer to APPENDICES A and B before reading this section.)

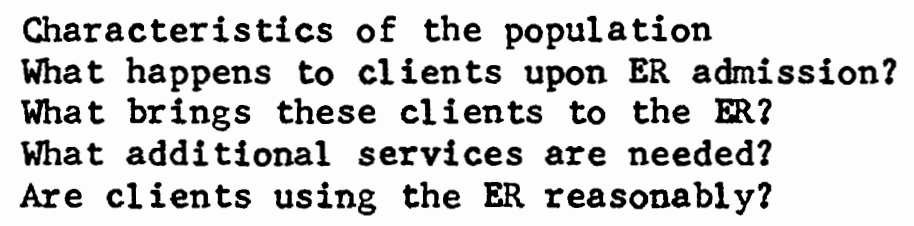

Most data discussed in the text relates to information collected from the total survey even though data from University of Oregon Heal th Sciences Center, other Multnomah County hospitals, and Clackamas and Washington County hospitals is presented separately in the tables. Each of the areas presented is followed by a brief discussion. The sum of the percentages in the tables may not equal $100.0 \%$ due to rounding conventions. 
CHAPTER II

MAJOR FINDINGS:

INTRODUCTION

Sixteen general hospitals in the Portland Tri-County area were asked to record information on emergency room admissions identified as having mental heal th problems. All but one hospital reported cases . appropriate to the study. Several hospitals reported that they had not completed a survey form for every client who would have been appropriate for inclusion in the study due to hospital policies, lack of time, and various other reasons. Therefore, the numbers reported here should be considered at least slightly low, even though there is no way to estimate what they should be.

One of the hospitals reporting, University of Oregon Health Sciences Center (UOHSC), accounted for over 50 percent of the clients included in the study. This hospital is affiliated with a university medical school, was until recently a county-operated facility, and may still be viewed as the most accessible place to go for treatment by non-paying clients. Because it represents such a large proportion of the clients studied, data for this hospital will be presented separate from that of the other hospitals in order to test that assumption. In addition, data from hospitals in Washington and Clackamas Counties is separated from Mul tnomah County data, since present planning efforts occur on an individual county basis.

One hospital conducted the survey from January 6, 1978 to February 
7, 1978. Al though there was no way to determine if the difference in the time period sampled would influence the data, since there was no basis for comparison, the data was included as though it covered the same time period as the other hospitals surveyed.

During the one-month period surveyed, 540 clients identifled as having mental health problems were reported as having been admitted to hospital ERs. The researchers had initially hoped to put this number into some kind of perspective by reporting an average number of all clients seen in hospital ERs monthly. However, this information was not readily available and would have required the expenditure of additional effort by the ERs, and the researchers did not want to impose on the ER staff. 


\section{CHAPTER III \\ MAJOR FINDINGS: \\ WHAT ARE THE CHARACTERISTICS \\ OF THIS POPULATION?}

The first question the researchers were interested in answering is: "Who are these clients whom ERs are identifying as having mental heal th problems?" How old are they, where do they live, do they have resources to cover hospital ER expenses, where are they going for services, and when are they going? How do they compare with the rest of Mul tnomah County?

Who Are These Gients?

(One hospital which participated in the survey did not report any demographic data.)

Address. Sixty-four point four percent of the total survey population is reported as living in Mul tnomah County. Residents of Clackamas County represented 6.5 percent of the clients studied, and Washington County residents accounted for four percent. Another 5.6 percent of the clients were from outside the Tri-County area, and 19.4 percent were unidentified as to residence. (See TABLE I for a more complete breakdown of the location of residences.)

Based on the location of residence, the differences between the 293 clients seen at UOHSC and the 247 clients seen at all other hospitals were subjected to a chi square test. There was no difference in 
drawing clients between UOHSC and the other hospitals. It appears that clients may not consider convenience (ie. the closest hospital) as the most important factor in choosing a hospital in a crisis.

TABLE I

LOCATION OF RESIDENCES OF CIENTS STUDIED

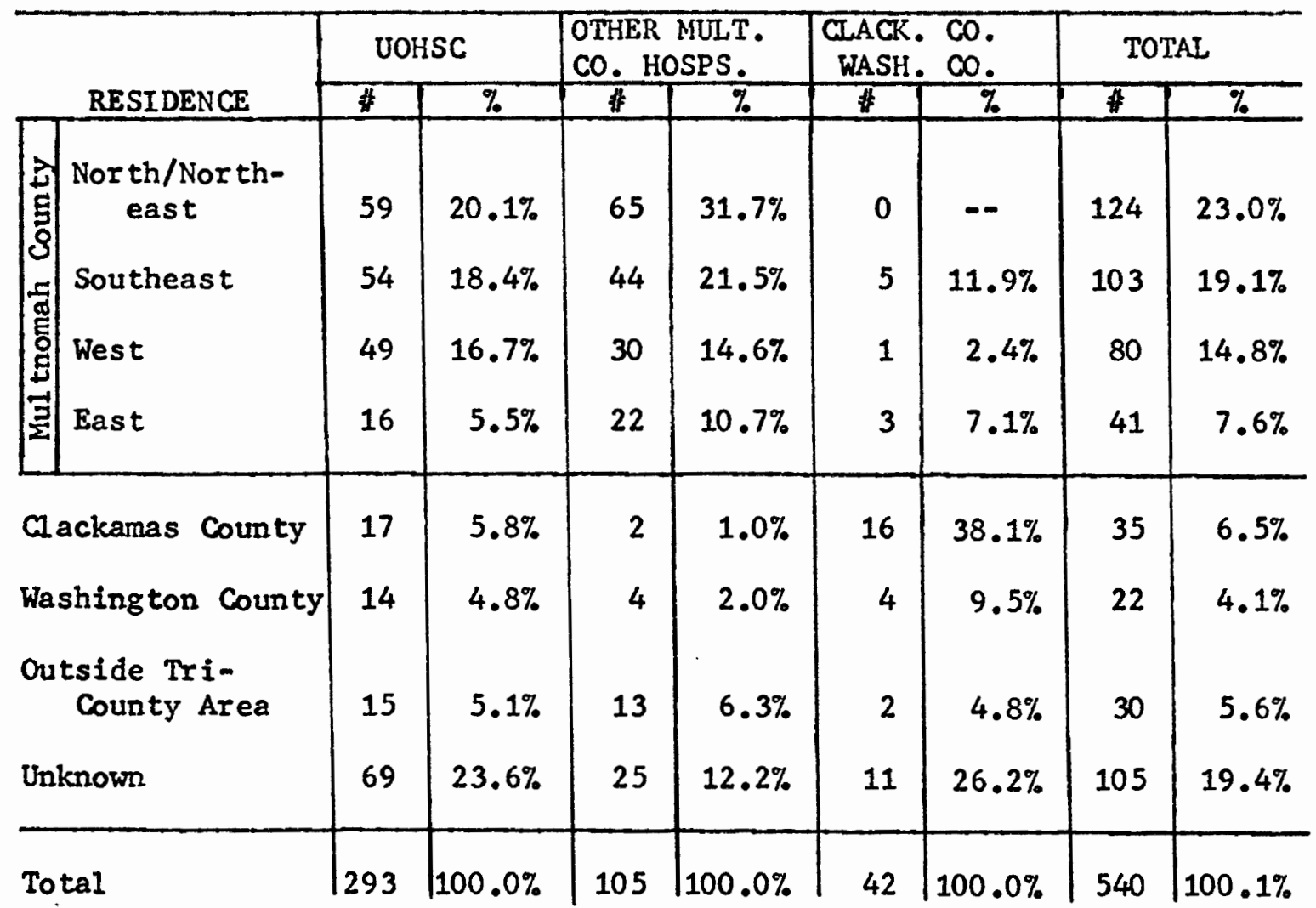

The location of the residences, by clinic quadrants, of the Multnomah County clients studied, differed significantly in proportion from the general population distribution of the county. Using the county population distribution proportions as the expected proportions, a chi square test was performed, and the differences proved to be significant to the .002 level. (Because of large disparity in the size of the numbers, it was necessary to use percentages in the computation of the chi 
square statistic.) As TABLE II shows, East County was represented in the study at a rate much lower than would be expected based on the general population distribution. The North/Northeast quadrant was highly overrepresented in the study. This information is presented in graphic form in Figure 1, so that the differences can be easily compared.

TABLE II

DISTRIBUTION OF SURVEY POPULATION (MULT. CO. RESIDENTS)

BY RESIDENCE COMPARED TO DISTRIBUTION OF MUITNOMAH

COUNTY GENERAL POPULATION BY RESIDENCE

\begin{tabular}{|c|c|c|c|c|c|}
\hline & \multicolumn{2}{|c|}{$\begin{array}{l}\text { MULTNOMAH COUNTY } \\
\text { SURVEY POPULATION }\end{array}$} & \multicolumn{2}{|c|}{$\begin{array}{l}\text { MULTNOMAH COUNTY } \\
\text { GENERAL POPULATION }\end{array}$} & \multirow{2}{*}{$\begin{array}{c}\text { DIFFERENCE IN } \\
\text { PERCENTAGE POINTS }\end{array}$} \\
\hline & \# & $\%$ & \# & $\%$ & \\
\hline North/Nor theast & 124 & $35.6 \%$ & 124,081 & $21.5 \%$ & +14.1 \\
\hline Southeast & 103 & $29.6 \%$ & 144,865 & $25.1 \%$ & +4.5 \\
\hline West & 80 & $23.0 \%$ & 90,000 & $15.6 \%$ & +7.4 \\
\hline East & 41 & $11.8 \%$ & 217,534 & $37.7 \%$ & -25.9 \\
\hline Total & 348 & $100.0 \%$ & 576,480 & $99.9 \%$ & \\
\hline
\end{tabular}

*Population projection obtained from the Center for Population Research and Census, Portland State University, Portland, Oregon, February, 1975.

Age. The ages of the clients surveyed ranged from three week to 88 years old. TABLE III. shows that the age group of 21 to 35 was the most frequently reported, accounting for just over half $(53.0 \%)$ of the clients surveyed. The age of only 19 clients (3.5\%) was unknown or not recorded, and these 19 clients were redistributed throughout the other items in this category and are not reported separately here. 


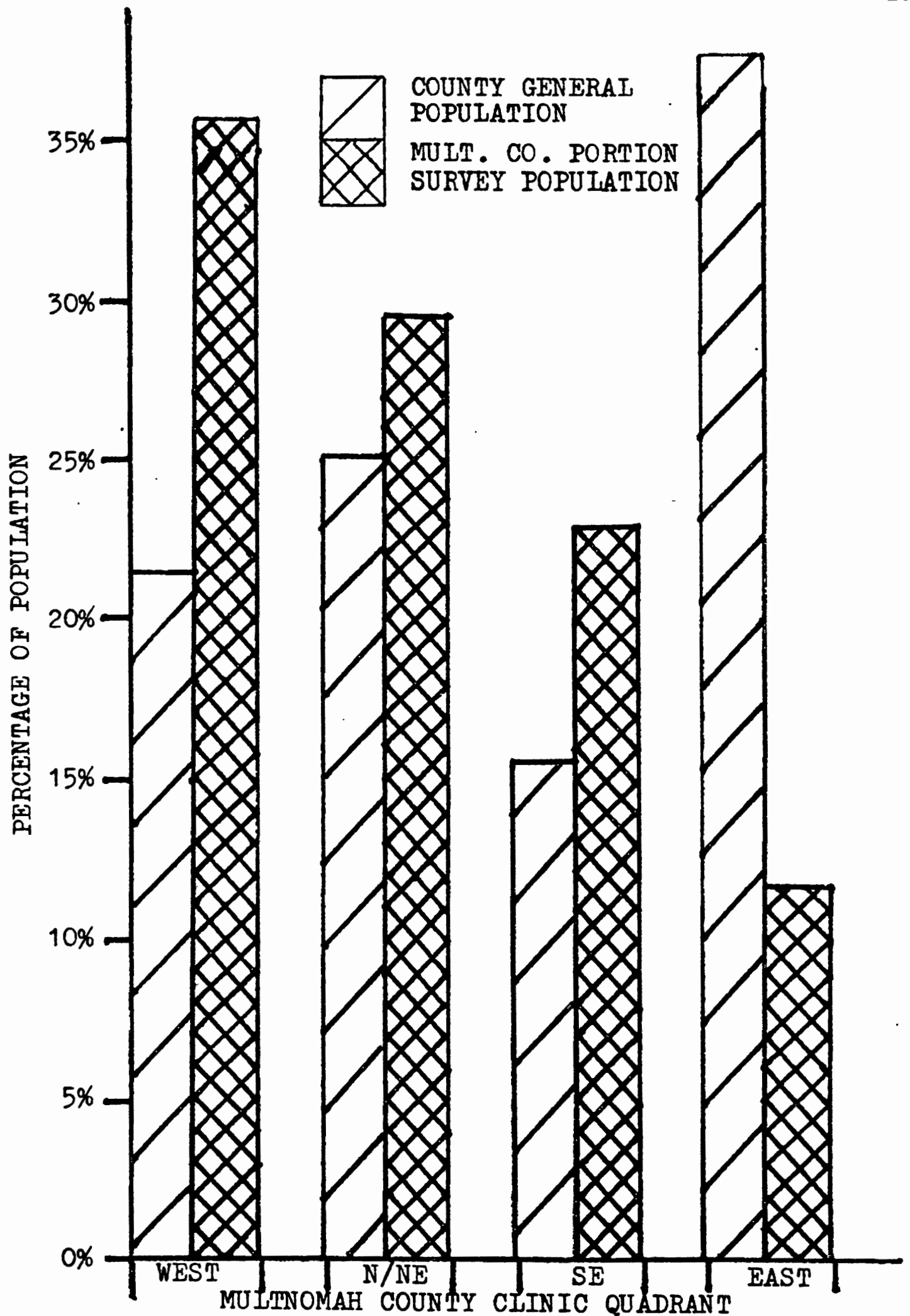

Figure 1. Comparison of residences of Multnomah County general population and Multnomah County portion of survey population. 
TABLE III

AGE DISTRIBUTION OF CIENTS STUDIED

\begin{tabular}{|c|c|c|c|c|c|c|c|c|}
\hline \multirow[b]{2}{*}{ AGE GROUPS } & \multicolumn{2}{|c|}{ UOHSC } & \multicolumn{2}{|c|}{$\begin{array}{l}\text { OTHER MULT. } \\
\text { CO. HOSPS. }\end{array}$} & \multicolumn{2}{|c|}{$\begin{array}{l}\text { CLACK. } \mathrm{CO} . \\
\text { WASH. } \mathrm{CO} .\end{array}$} & \multicolumn{2}{|c|}{ TOTAL } \\
\hline & \# & $\%$ & \# & $\%$ & \# & $\%$ & 坓 & $\%$ \\
\hline $0-15$ Years & 6 & $2.1 \%$ & 12 & $5.9 \%$ & 5 & $11.9 \%$ & 23 & $4.1 \%$ \\
\hline $16-20$ Years & 37 & $12.6 \%$ & 22 & $10.7 \%$ & 6 & $14.3 \%$ & 65 & $12.0 \%$ \\
\hline 21-35 Years & 170 & $58.0 \%$ & 99 & $48.1 \%$ & 17 & $40.5 \%$ & 268 & $53.0 \%$ \\
\hline $36-50$ Years & 53 & $18.1 \%$ & 43 & $21.0 \%$ & 9 & $21.4 \%$ & 105 & $19.4 \%$ \\
\hline 51 and 01 der & 27 & $9.2 \%$ & 29 & $14.2 \%$ & 5 & $11.9 \%$ & 61 & $11.3 \%$ \\
\hline Total & 293 & $100.0 \%$ & 205 & $99.9 \%$ & 42 & $100.0 \%$ & 540 & $99.8 \%$ \\
\hline
\end{tabular}

The differences in age distribution between UOHSC and other hospitals surveyed proved significant to the .02 level. The age group 21-35 is responsible for the largest difference. UOHSC reports a much higher frequency of clients in this age group than expected, and all other hospitals report lower-than-expected frequencies.

In comparing the age distribution of surveyed clients from Mul tnomah county, the researchers again found significant differences. The application of chi square tests showed the differences significant to the .002 level. Specifically, the age group 21-35 years old was overrepresented in the survey population by 30 percentage points; the lowest age group 0-15 years old was underrepresented by 22 percentage points, and the oldest age group, 51 and over, was underrepresented by 18 percentage points among the Multnomah County-resident portion of the clients studied. (Again it was necessary to use percentages to compute the chi square statistic.) See TABLE IV. 
TABLE IV

DISTRIBUTION OF SURVEY POPULATION (MULT. CO. RESIDENTS)

BY AGE COMPARED TO DISTRIBUTION OF MUL TNOMAH

COUNTY GENERAL POPULATION BY AGE*

\begin{tabular}{|c|c|c|c|c|c|}
\hline \multirow[b]{2}{*}{ AGE } & \multicolumn{2}{|c|}{$\begin{array}{l}\text { MULTNOMAH COUNTY } \\
\text { SURVEY POPULATI ON }\end{array}$} & \multicolumn{2}{|c|}{$\begin{array}{l}\text { MULTNOMAH COUNTY } \\
\text { GENERAL POPULATION }\end{array}$} & \multirow{2}{*}{$\begin{array}{l}\text { DIFFERENCE IN } \\
\text { PERCENTAGE } \\
\text { POINTS } \\
\end{array}$} \\
\hline & $\#$ & $\%$ & $\#$ & $\%$ & \\
\hline $0-15$ Years & 15 & $4.3 \%$ & 147,588 & $26.5 \%$ & -22.2 \\
\hline 16-20 Years & 46 & $13.2 \%$ & 49,987 & $9.0 \%$ & +4.2 \\
\hline 21-35 Years & 172 & $49.4 \%$ & 105,744 & $19.0 \%$ & +30.4 \\
\hline 36-50 Years & 77 & $22.1 \%$ & 90,172 & $16.2 \%$ & +5.9 \\
\hline 51 and 01 der & 38 & $10.9 \%$ & 163,175 & $29.3 \%$ & -18.4 \\
\hline Total & 348 & $99.9 \%$ & 556,666 & $100.0 \%$ & \\
\hline
\end{tabular}

This comparison is presented in graphic form in Figure 2.

Sex. Hospital ER staff reported that the clients were almost evenly divided among males and females, with females representing a slightly higher percentage. Unrecorded responses represented 3.3 percent of the total, and were distributed throughout the other items in preparing TABLE V.

There were no significant differences in sex for vOHSC clients and those of other hospitals surveyed.

TABLE VI shows that the portion of the survey population residing In Multnomah County was also almost evenly divided among males and females, with 2.0 percent unrecorded and redistributed. These proportions were virtually identical to those in the county general population. 


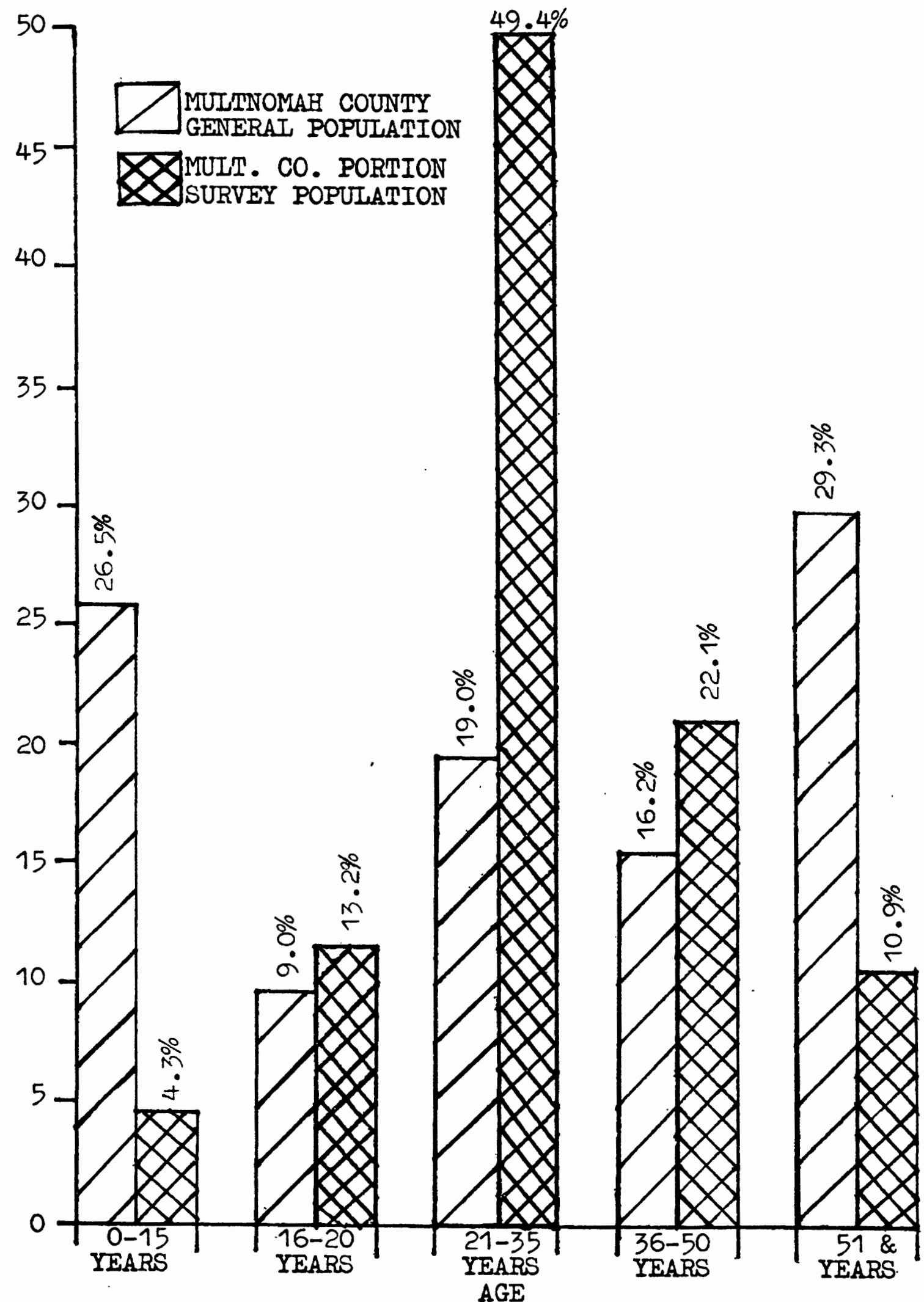

Figure 2. Distribution of age in Multnomah County general population and Multnomah County portion of survey population. 
TABLE V

DISTRIBUTION OF MALES AND FEMALES WITHIN

POPULATION OF CLIENTS STUDIED

\begin{tabular}{|c|c|c|c|c|c|c|c|c|}
\hline \multirow[b]{2}{*}{ SEX } & \multicolumn{2}{|c|}{ UOHSC } & \multicolumn{2}{|c|}{$\begin{array}{l}\text { OTHER MULT. } \\
\mathrm{CO} \text {. HOSPS. }\end{array}$} & \multicolumn{2}{|c|}{$\begin{array}{l}\text { CLACK. } \mathrm{CO} . \\
\text { WASH. } \mathrm{CO} \text {. }\end{array}$} & \multicolumn{2}{|c|}{ TOTAL } \\
\hline & $\#$ & $\%$ & $\#$ & $\%$ & $\#$ & $\%$ & $\#$ & $\%$ \\
\hline Female & 154 & $52.6 \%$ & 107 & $52.2 \%$ & 25 & $59.5 \%$ & 286 & $53.0 \%$ \\
\hline Male & 139 & $47.4 \%$ & 98 & $47.8 \%$ & 17 & $40.5 \%$ & 254 & $47.0 \%$ \\
\hline Total & 293 & $100.0 \%$ & 205 & $100.0 \%$ & 42 & $100.0 \%$ & 540 & $100.0 \%$ \\
\hline
\end{tabular}

TABLE VI

COMPARISON OF MALE TO FEMALE PROPORTIONS IN THE SURVEY

POPULATION (MULT. CO. RESIDENTS) AND IN THE

MULTNOMAH COUNTY GENERAL POPULATION *

\begin{tabular}{|c|c|c|c|c|c|}
\hline \multirow[b]{2}{*}{ SEX } & \multicolumn{2}{|c|}{$\begin{array}{l}\text { MULTNOMAH COUNTY } \\
\text { SURVEY POPULATION }\end{array}$} & \multicolumn{2}{|c|}{$\begin{array}{l}\text { MULTNOMAH COUNTY } \\
\text { GENERAL POPULATION }\end{array}$} & \multirow{2}{*}{$\begin{array}{l}\text { DIFFERENCE IN } \\
\text { PERCENTAGE } \\
\text { POINTS } \\
\end{array}$} \\
\hline & 4 & $\%$ & . & $\%$ & \\
\hline Female & 182 & $52.3 \%$ & 292,129 & $52.5 \%$ & -0.2 \\
\hline Male & 166 & $47.7 \%$ & 264,537 & $47.5 \%$ & +0.2 \\
\hline Total & 348 & $100.0 \%$ & 556,666 & $100.0 \%$ & \\
\hline
\end{tabular}

*Data from the Population Characteristics of the 1970 Census.

Insurance coverage. An examination of the data provided by ER staff on insurance coverage revealed very little difference between the three major groupings. Those clients having no insurance represented the largest proportion of those surveyed (29.7\%), with other third-party coverage (welfare, county contract, etc.) a close second (28.0\%). Those 
with insurance totalled 24.6 percent. Insurance coverage for 17.8 percent of the clients was unknown or unrecorded. (See TABLE VII.)

TABLE VII

INSURANCE COVERAGE FOR CIIENTS STUDIED

\begin{tabular}{|c|c|c|c|c|c|c|c|c|}
\hline \multirow{2}{*}{$\begin{array}{l}\text { INSURANCE } \\
\text { COVERAGE }\end{array}$} & \multicolumn{2}{|c|}{ UOHSC } & \multicolumn{2}{|c|}{$\begin{array}{l}\text { OTHER MULT. } \\
\text { CO. HOSPS. }\end{array}$} & \multicolumn{2}{|c|}{$\begin{array}{l}\text { CLACK. } \mathrm{CO} . \\
\text { WASH. } \mathrm{CO} \text {. }\end{array}$} & \multicolumn{2}{|c|}{ TOTAL } \\
\hline & IE & $\%$ & $\#$ & $\%$ & 7 & $\%$ & $\#$ & 7 \\
\hline Insurance & 32 & $10.9 \%$ & 85 & $41.5 \%$ & 16 & $38.1 \%$ & 133 & $24.6 \%$ \\
\hline Other 3rd-Party & 107 & $36.5 \%$ & 39 & $19.0 \%$ & 5 & $11.9 \%$ & 151 & $28.0 \%$ \\
\hline None & 105 & $35.8 \%$ & 46 & $22.4 \%$ & 9 & $21.4 \%$ & 160 & $29.6 \%$ \\
\hline Unknown & 49 & $16.7 \%$ & 35 & $17.1 \%$ & 12 & $28.6 \%$ & 96 & $17.8 \%$ \\
\hline Total & 293 & $99.9 \%$ & 205 & $100.0 \%$ & 42 & $100.0 \%$ & 540 & $100.0 \%$ \\
\hline
\end{tabular}

These differences proved significant to the .001 level when UOHSC was compared to all other hospitals.

To Which Hospitals Are Gients Going?

Fifteen Tri-County hospitals participating in the survey reported a total of 540 clients who were identified by the ER staff as having mental heal th problems during the one-month period of the survey. An examination of TABLE VIII reveals that 498 of these clients were reported by the ten hospitals surveyed in Multnomah County. Thirty-three were reported from Clackamas County hospitals, and nine from Washington Coun* ty. 
TABLE VIII

NUMBER OF CIENTS IDENTIFIED AS HAVING MENTAL HEALTH

BY INDIVIDUAL HOSPITALS REPORTING

\begin{tabular}{|c|c|c|c|c|}
\hline \multicolumn{2}{|c|}{ LOCATION } & HOSPITAL & $\#$ & $\%$ \\
\hline \multirow{4}{*}{ 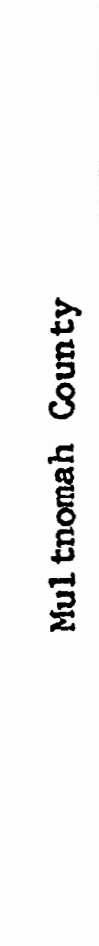 } & 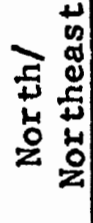 & $\begin{array}{l}\text { Emanuel Hospital } \\
\text { Holladay Park Hospital } \\
\text { Providence Medical Center }\end{array}$ & $\begin{array}{l}46 \\
38 \\
42\end{array}$ & $\begin{array}{l}8.5 \% \\
7.0 \% \\
7.8 \%\end{array}$ \\
\hline & 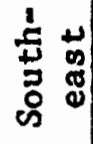 & $\begin{array}{l}\text { Eastmoreland General Hospital } \\
\text { Woodland Park Mental Health Center }\end{array}$ & $\begin{array}{r}3 \\
14\end{array}$ & $\begin{array}{l}0.6 \% \\
2.6 \%\end{array}$ \\
\hline & 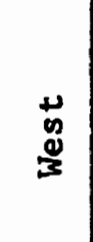 & $\begin{array}{l}\text { Good Samaritan Hospital \& Medical Center } \\
\text { Physicians \& Surgeons Hospital } \\
\text { University of Oregon Health Sciences Center }\end{array}$ & $\begin{array}{r}13 \\
13 \\
293\end{array}$ & $\begin{array}{l}2.4 \% \\
2.4 \% \\
54.3 \%\end{array}$ \\
\hline & 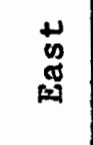 & $\begin{array}{l}\text { Gresham Community Hospital } \\
\text { Portland Adventist Medical Center }\end{array}$ & $\begin{array}{l}25 \\
11\end{array}$ & $\begin{array}{l}4.6 \% \\
2.0 \%\end{array}$ \\
\hline 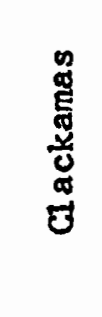 & $\stackrel{\$}{\Xi}$ & $\begin{array}{l}\text { Dwyer Memorial Hospital \& Medical Center } \\
\text { Meridian Park Hospital } \\
\text { Sunnyside Medical Center } \\
\text { Willamette Falls Community Hospital }\end{array}$ & $\begin{array}{r}7 \\
10 \\
6 \\
10\end{array}$ & $\begin{array}{l}1.3 \% \\
1.9 \% \\
1.1 \% \\
1.9 \%\end{array}$ \\
\hline 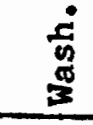 & $\dot{8}$ & St. Vincent Hospital \& Medical Center & 9 & $1.7 \%$ \\
\hline & & Total & 540 & $100.1 \%$ \\
\hline
\end{tabular}


When Are These Clients Being Seen?

Several problems were encountered in reviewing the data on when these clients were being admitted to the ER. One of these problems involved the fact that not all days of the week were equally represented during the survey period. For example, the period Dec. 15, 1977 to Jan. 15, 1978 included five Sundays, Thursdays, Fridays, and Saturdays, but only four Mondays, Tuesdays, and Wednesdays.

After analyzing the data in several ways, the information still appeared to hold the same basic internal relationship as when viewed in raw form. Because of this, the researchers decided to present the data initially as though the days of the week were represented equally for the sake of simplicity.

In addition, data from one hospital which conducted the survey during a slightly later but overlapping time period is included with the data from the earlier period, since there is no way to determine what factors might have affected the data.

Day of week. The researchers were interested in determining whether clients with mental heal th problems were more likely to be seen on one day of the week rather than another. The possibility existed that clients might utilize the ER more on week-ends when many mental heal th agencies are closed. While the data presented in TABLE IX provides some support for this theory, the evidence is far from clear cut. In comparing the frequency with which clients were seen on each day of the week for UOHSC and other hospitals, the differences proved significant to the .002 level. On Sundays and Mondays, proportionately more clients were seen at other hospitals than at UOHSC. On Thursdays 
and Fridays, proportionately more clients were seen at voHSC than at other hospitals.

\section{TABLE IX}

NUMBER OF CLIENTS ADNT TTED BY DAY

OE WEEK ON WHICH ADMI TTED

\begin{tabular}{|c|c|c|c|c|c|c|c|c|}
\hline & \multicolumn{2}{|c|}{ UOHSC } & \multicolumn{2}{|c|}{$\begin{array}{l}\text { OTHER MULT. } \\
\text { CO. HOSPS. }\end{array}$} & \multicolumn{2}{|c|}{$\begin{array}{l}\text { CLACK. } \mathrm{CO} \\
\text { WASH. } \infty \mathbf{}\end{array}$} & \multicolumn{2}{|c|}{ TOTAI } \\
\hline & \# & $\%$ & $\#$ & $\%$ & 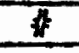 & $\%$ & $\$$ & $\%$ \\
\hline Sunday & 28 & $9.6 \%$ & 36 & $17.6 \%$ & 8 & $19.1 \%$ & 72 & $13.3 \%$ \\
\hline Monday & 31 & $10.6 \%$ & 40 & $19.5 \%$ & 1 & $2.4 \%$ & 72 & $13.3 \%$ \\
\hline Tuesday & 38 & $13.0 \%$ & 32 & $15.6 \%$ & 4 & $9.5 \%$ & 74 & $13.7 \%$ \\
\hline Wednesday & 28 & $9.6 \%$ & 23 & $11.2 \%$ & 9 & $21.4 \%$ & 60 & $11.1 \%$ \\
\hline Thursday & 59 & $20.1 \%$ & 18 & $8.8 \%$ & 9 & $21.4 \%$ & 86 & $15.9 \%$ \\
\hline Friday & 57 & $19.5 \%$ & 26 & $12.7 \%$ & 6 & $14.3 \%$ & 89 & $16.5 \%$ \\
\hline Saturday & 52 & $17.8 \%$ & 30 & $14.6 \%$ & 5 & $11.9 \%$ & 87 & $16.1 \%$ \\
\hline Total & 293 & $100.2 \%$ & 205 & $100.0 \%$ & 42 & $100.0 \%$ & 540 & $99.9 \%$ \\
\hline
\end{tabular}

Time of day. There was some expectation on the part of the researchers that a higher frequency of mental health problems would be seen during the evening and early morning hours than during the rest of the day, again because most mental heal th agencies are closed during these hours. The twenty-four hours of the day were divided in four 6hour periods to test this hypothesis.

As shown in TABLE $\mathrm{X}$, the time period 6 " p.m. to midnight had the highest frequency of clients with mental heal th problems, accounting for 34.3 percent of the clients reported. The second highest frequency was 
seen from Noon to 6 p.m. (27.6\%), contrary to the researchers expectations. The evening and early morning hours did, however, account for over half of the clients (55.6\%).

TABLE X

NUMBER OF CLIENTS ADMITTED

BY TIME OF DAY ADMITTED

\begin{tabular}{|c|c|c|c|c|c|c|c|c|}
\hline \multirow[b]{2}{*}{ TIME OF DAY } & \multicolumn{2}{|c|}{ UOHSC } & \multicolumn{2}{|c|}{$\begin{array}{l}\text { OTHER MULT. } \\
\text { CO. HOSPS. }\end{array}$} & \multicolumn{2}{|c|}{$\begin{array}{l}\text { CLACK. }{ }^{C 0} \text {. } \\
\text { CASH }\end{array}$} & \multicolumn{2}{|c|}{ TOTAL } \\
\hline & \# & $\%$ & If & $\%$ & $\#$ & $\%$ & 量 & $\%$ \\
\hline $\begin{array}{c}\text { Midnight to } \\
6 \mathrm{am}\end{array}$ & 53 & $18.1 \%$ & 55 & $26.8 \%$ & 7 & $16.7 \%$ & 115 & $21.3 \%$ \\
\hline 6 am to Noon & 54 & $18.4 \%$ & 30 & $14.6 \%$ & 7 & $16.7 \%$ & 91 & $16.9 \%$ \\
\hline Noon to $6 \mathrm{pm}$ & 95 & $32.4 \%$ & 43 & $21.0 \%$ & 11 & $26.2 \%$ & 149 & $27.6 \%$ \\
\hline $\begin{array}{l}6 \mathrm{pm} \text { to } \\
\text { Midnight }\end{array}$ & 91 & $31.1 \%$ & 77 & $37.6 \%$ & 17 & $40.5 \%$ & 185 & $34.3 \%$ \\
\hline Total & 293 & $100.0 \%$ & 205 & $100.0 \%$ & 42 & $100.1 \%$ & 540 & $100.1 \%$ \\
\hline
\end{tabular}

The frequencies for different times of day were not significantly different between vOHSC and other hospitals.

The data from the two previously examined categories was crosstabulated to give a more complete picture of ER usage by clients with mental heal th problems. The unequal distribution of the days of the week during the survey period was taken into account in these calculations.

The data was separated by the day of the week on which the client came to the ER. Then, for each day of the week, it was separated and counted by the specific 6-hour time period in which the client entered the ER. From this information, the average number of daily clients for 
each 6-hour time period was calculated by dividing the number of clients seen in each period by the number of times that day occurred during the course of the survey.

For example, a total of 14 clients entered the ER between midnight and 6 am on the Thursdays of the survey. The survey included five Thursdays, so 14 was divided by 5 to get an average of 2.8 clients between midnight and 6 am on each of the Thursdays in the survey.

After this was done for each of the twenty-eight 6-hour periods, the average number of clients for all periods were added to determine the average number of weekly clients, 117.2 , and the percentage of weekly clients represented by each 6 -hour time period was calculated. This information is presented in Figure 3.

\section{Discussion}

In analyzing the general characteristics of this population, several descriptive qualities emerge. First, one observes that while only 65 percent of ER-served clients reside in Multnomah County, 92 percent were seen in Multnomah County-based hospitals. Such usage pattern is curious when it is recognized that one third of the hospitals participating in the survey are located outside Multnomah County. The issue of why clients do not utilize the services of an ER nearest their residence, however, may be somewhat clarified when it is recalled that 54 percent are served by UOHSC, and particularly a higher proportion of medically indigent clients. This may reflect a tendency on the part of the general public to identify this state-supported institution (which at one time included a "county hospital" and whose psychiatric service is referred to as the "Crisis Unit") as the place to seek help when 


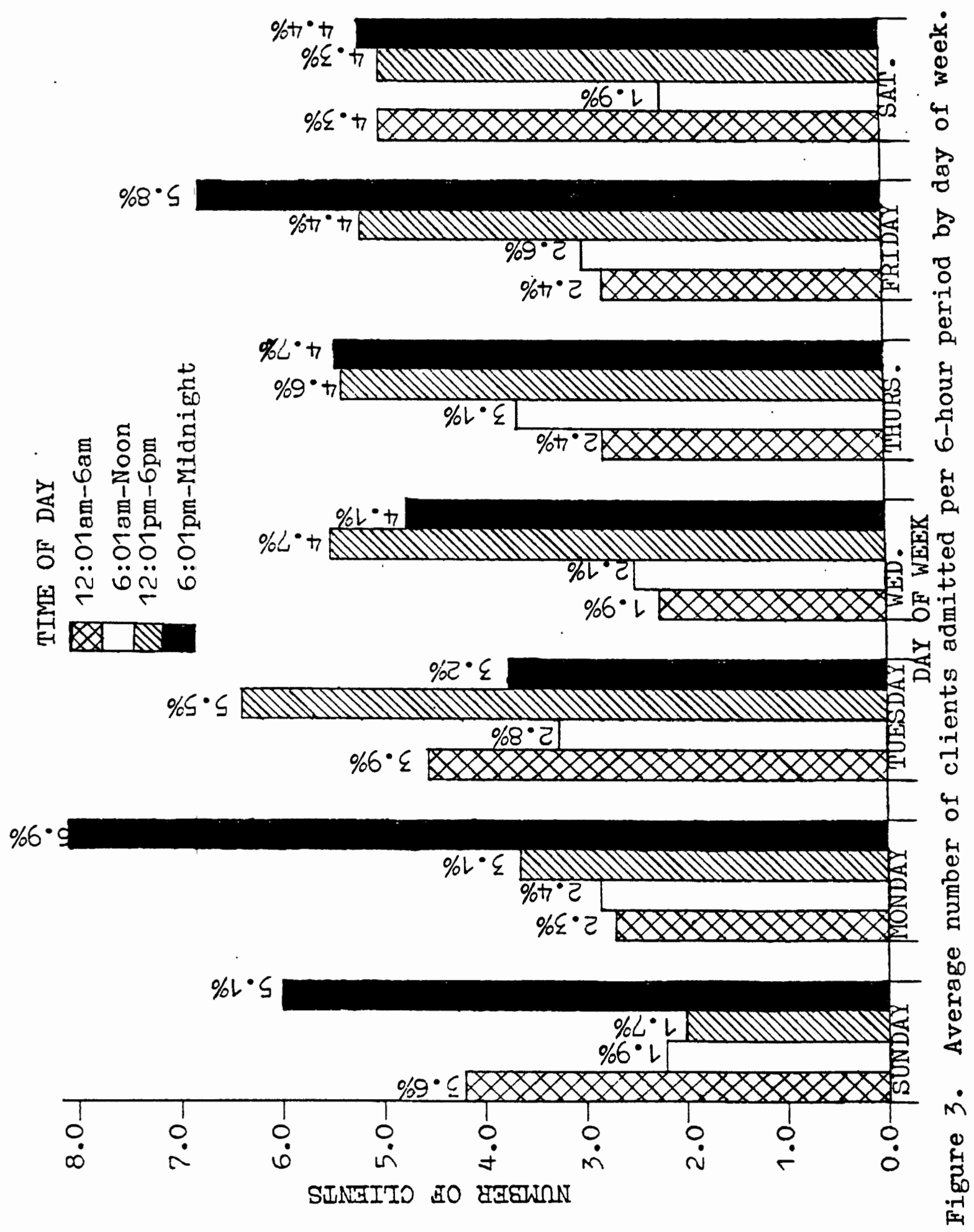


facing a mental heal th emergency.

Residents in the North/Northeast section of the County are overrepresented vis a vis the general population distribution in Multnomah County. This is not surprising if one accepts the relationship between socio-economic factors and the incidence of psychiatric disorders. The Multnomah County Mental Health P1an for 1977-78 indicates that this quadrant is one of the poorest in the County with 12 percent of all families living below poverty level.

One third of the population surveyed was identified as unable to pay for care either through insurance or other third-party payors. This characteristic points out the financial responsibility which hospitals are assuming, since they cannot refuse service to any clients presenting themselves in the ER.

In addition, young adults (21-35 years of age) are being served by ERs more frequently than children or the elderly. This characteristic may not reflect the incidence of mental heal th problems, but simply may suggest their ability and proclivity to use that service rather than another source of help.

While there is a higher frequency of admissions on Thursdays and Fridays at UOHSC, and on Sundays and Mondays at other hospitals, and during the hours of $6 \mathrm{pm}$ and 6 am for all hospitals, emergency room usage is still quite scattered. 


\section{CHAPTER IV \\ MAJOR FINDINGS:}

WHAT HAPPENS TO THE CLIENT UPOI ER ADMISSION?

The researchers were interested in finding out what type of treatment or services are being administered to clients with mental heal th problems in the ER. Are they being hospitalized or referred to other, perhaps more appropriate, services, and how much time are they spending in the ER?

How Long Are Clients Spending in the ER?

There are several possible implications of this type of information. If the data included information about the amount of time each client spent in direct contact with ER staff, it could be used as a measure of cost-effectiveness of this type of treatment as opposed to treatment in a mental heal th-oriented agency. This type of information is not available from this study, but it points up an area which should be the focus of some future study.

Another use of this type of information lies in determining if the amount of waiting time is a significant factor in whether a client with a mental heal th problem chooses an ER or a mental health agency for service or treatment. However, additional study is necessary to obtain this type of information in relation to mental heal th agencies in order to make the comparison.

Although it is not possible to deal with either of these implica- 
tions at present, the available information is reported here so that it will be readily available when needed.

Data reported here was calculated from "time of entry" and "time of discharge" information. While the unrecorded responses amounted to less than three percent of the total for "time of entry," they totaled 27.8 percent of the responses to "time of discharge."

The single largest category under "length of stay" was one to two hours, accounting for one-third $(33.5 \%)$ of the total responses. Twentytwo point eight percent of the clients spent two to four hours in the ER, 14.1 percent spent less than one hour, and only 2.6 percent were there for more than four hours. (See TABLE XI.)

\section{TABLE XI}

\section{LENGTH OF STAY IN THE ER}

\begin{tabular}{|c|c|c|c|c|c|c|c|c|}
\hline & \multicolumn{2}{|c|}{ UOHSC } & \multicolumn{2}{|c|}{$\begin{array}{l}\text { OTHER WULT. } \\
\text { CO. HOSPS. }\end{array}$} & \multicolumn{2}{|c|}{$\begin{array}{l}\text { CLACK. CO. } \\
\text { WASH. CO. }\end{array}$} & \multicolumn{2}{|c|}{ TOTAL } \\
\hline & \# & $\%$ & 涪 & $\%$ & \# & $\%$ & \# & $\%$ \\
\hline $\begin{array}{l}\text { Less than } \\
\text { one hour }\end{array}$ & 25 & $8.5 \%$ & 46 & $22.4 \%$ & 5 & $11.9 \%$ & 76 & $14.1 \%$ \\
\hline $\begin{array}{l}\text { One to } \\
\text { two hours }\end{array}$ & 96 & $32.8 \%$ & 66 & $32.2 \%$ & 19 & $45.2 \%$ & 181 & $33.5 \%$ \\
\hline $\begin{array}{l}\text { Two to } \\
\text { four hours }\end{array}$ & 70 & $23.9 \%$ & 40 & $19.5 \%$ & 9 & $21.4 \%$ & 119 & $22.0 \%$ \\
\hline $\begin{array}{l}\text { More than } \\
\text { four hours }\end{array}$ & 10 & $3.4 \%$ & 4 & $2.0 \%$ & 0 & $m$ & 14 & $2.6 \%$ \\
\hline Unrecorded & 92 & $31.4 \%$ & 49 & $23.9 \%$ & 9 & $21.4 \%$ & 150 & $27.8 \%$ \\
\hline Total & 293 & $100.0 \%$ & 205 & $100.0 \%$ & 42 & $99.9 \%$ & 450 & $100.0 \%$ \\
\hline
\end{tabular}


In comparing the length of stay at UOHSC to length of stay at other hospitals, the differences were found significant to the .02 level. Specifically, UOHSC had a higher proportion of clients spending two to four hours in the ER and a lower proportion of clients staying less than one hour than the other hospitals.

\section{What Are Clients Receiving in the ER?}

Treatment received. This category of information carried implications for determining whether clients with mental heal th problems can receive the treatment and services they need through existing mental heal th agencies, and in determining the additional types of services needed.

TABLE XII shows that the largest proportion of the total survey population received assessment, diagnosis, and medical attention ( $31.5 \%$ ). Assessment, diagnosis, and psychiatric admission accounted for 24.8 percent of the treatment received. Twenty point seven percent of the survey population received assessment, diagnosis, and agency referral, and 23.0 percent received assessment, diagnosis, and supportive therapy. The differences between the observed and expected frequencies in computing the chi square test for UOHSC and the other hospitals were very large for all categories. The test proved significance to the .002 level, and the category which included medical attention exhibited the largest difference: UOHSC reported a proportionately lower frequency of clients receiving medical attention than did the other hospitals. UOHSC reported a proportionately higher frequency in supportive thexapy, agency referral, and psychiatric admissions. 
TABLE XII

EMERGEICY ROOM TREATHENT

\begin{tabular}{|c|c|c|c|c|c|c|c|c|}
\hline \multirow[b]{2}{*}{ TREATMIENT } & \multicolumn{2}{|c|}{ UOHSC } & \multicolumn{2}{|c|}{$\begin{array}{l}\text { OTHER MULT. } \\
\text { CO. HOSPS. }\end{array}$} & \multicolumn{2}{|c|}{$\begin{array}{l}\text { CACK. } \mathrm{CO} . \\
\text { WASH: } \mathrm{CO} .\end{array}$} & \multicolumn{2}{|c|}{ TOTAL } \\
\hline & \# & $\%$ & \# & $\%$ & 非 & $\%$ & 釉 & $\%$ \\
\hline $\begin{array}{l}\text { Assessment/ } \\
\text { Diagnosis/ } \\
\text { Supportive } \\
\text { Therapy }\end{array}$ & 86 & $29.4 \%$ & 32 & $15.6 \%$ & 6 & $14.3 \%$ & 124 & $23.0 \%$ \\
\hline $\begin{array}{l}\text { Assessnent/ } \\
\text { Diagnosis/ } \\
\text { Agency } \\
\text { Referral } \\
\end{array}$ & 75 & $25.6 \%$ & 32 & $15.6 \%$ & 5 & $11.9 \%$ & 112 & $20.7 \%$ \\
\hline $\begin{array}{l}\text { Assessment/ } \\
\text { Diagnosis/ } \\
\text { Medical } \\
\text { Attention } \\
\end{array}$ & 35 & $12.0 \%$ & 111 & $54.2 \%$ & 24 & $57.1 \%$ & 170 & $31.5 \%$ \\
\hline $\begin{array}{l}\text { Assessment/ } \\
\text { Diagnosis/ } \\
\text { Psychiatric } \\
\text { Adnission }\end{array}$ & 97 & $33.1 \%$ & 30 & $14.6 \%$ & 7 & $16.7 \%$ & 134 & $24.8 \%$ \\
\hline Total & 293 & $100.1 \%$ & 205 & $100.0 \%$ & 42 & $100.0 \%$ & 540 & $100.0 \%$ \\
\hline
\end{tabular}

Hospitalizations. One hundred eighty-seven (34.6\%) of the 540 clients surveyed were hospitalized, either medically or psychiatrically. More than one-quarter of those hospitalized went to Damnasch State Hospital and another quarter were hospitalized at UOHSC. Another quarter were hospitalized at the other four hospitals in Multnomah County with psychiatric inpatient units. This data is presented in TABLE XIII.

One hundred thirty-four clients received a psychiatric admission (see Energency Room Treatment, TABLE XII) indicating that 53 of the 187 hospitalizations were in medical units.

Only the data on whether or not a client was hospitalized was subjected to a chi square test. This test showed no significant difference between UOHSC and other hospitals in relation to hospitalizations. 
TABLE XIII

HOSPITALIZATIONS

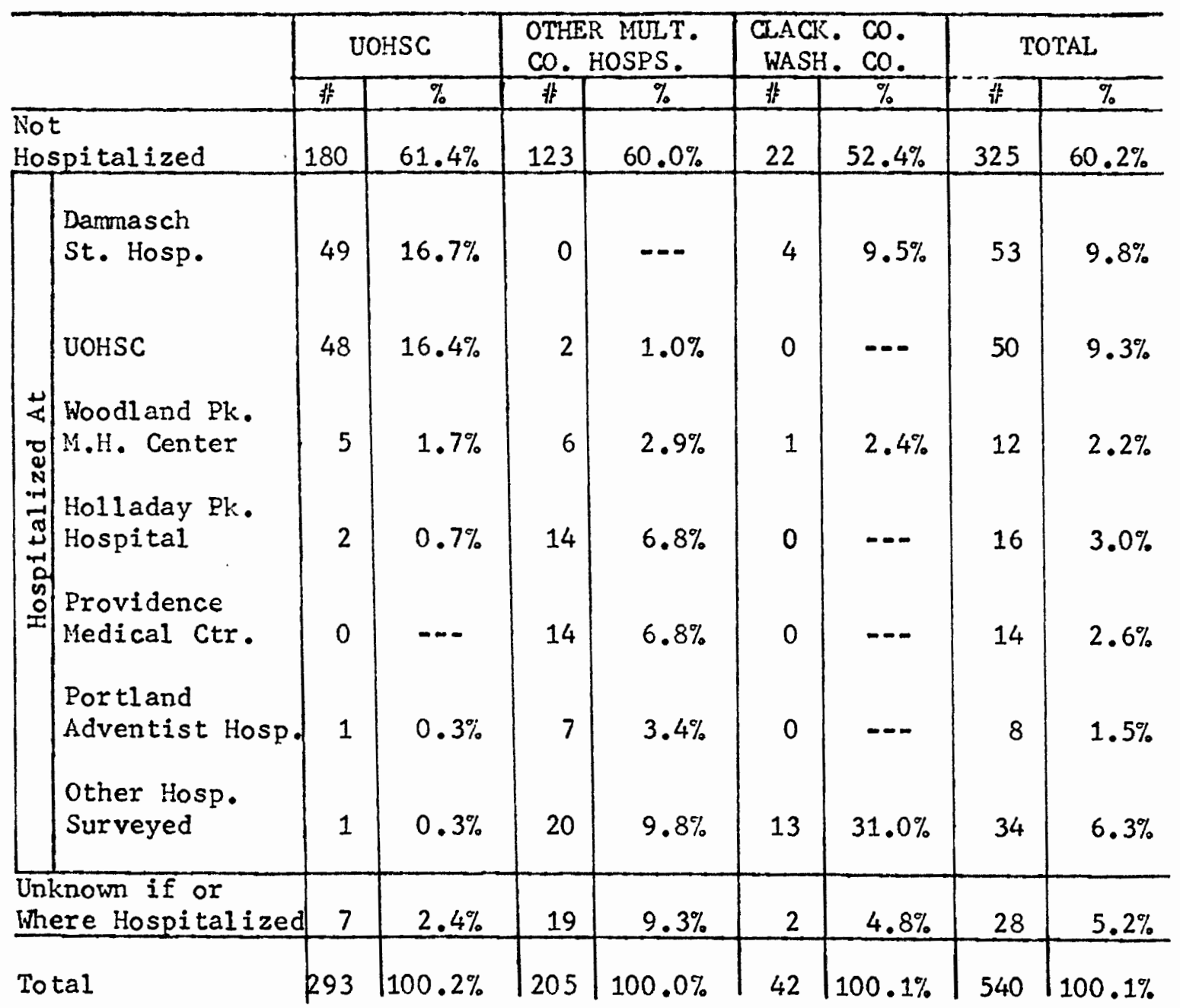

Referrals. Just over half of the clients surveyed (51.7\%) received a referral for additional services. This number is greater than the number of clients included as receiving an agency referral under the heading "ER Treatment." The difference results from clients who received medical attention and an agency referral for mental heal th problems; those clients who received a referral to another facility for psychiatric hospitalization; and those clients who received supportive therapy or medi- 
cal attention and a referral to the in-house outpatient or social services department (which was not considered a referral for the category of Emergency Room Treatment).

The referrals were made to a wide variety of agencies, with no one type of agency standing out from the others. (See TABLE XIV.)

The only data in this category subjected to a chi square test was whether or not clients received a referral. The differences were significant to the .002 level: UOHSC reported a proportionately higher frequency of clients who received a referral than did the other hospitals surveyed.

Court holds. A total of 58 clients were detained on a Notice of Mental Illness. This represents 10.7 percent of the study population. Fifty-six of these court holds were reported by UOHSC; Clackamas and Washington Counties each reported one court hold. No court holds were reported by other Multnomah County hospitals.

Data from the age, sex, referral source, time of day, and day of week categories was cross-tabulated with court holds to provide additional information on this subgroup of the study population. The results of this cross-tabulation are presented in TABLES XV, XVI, XVII, $X V I I I$, and $X I X$. 
TABLE XIV

REFERRALS

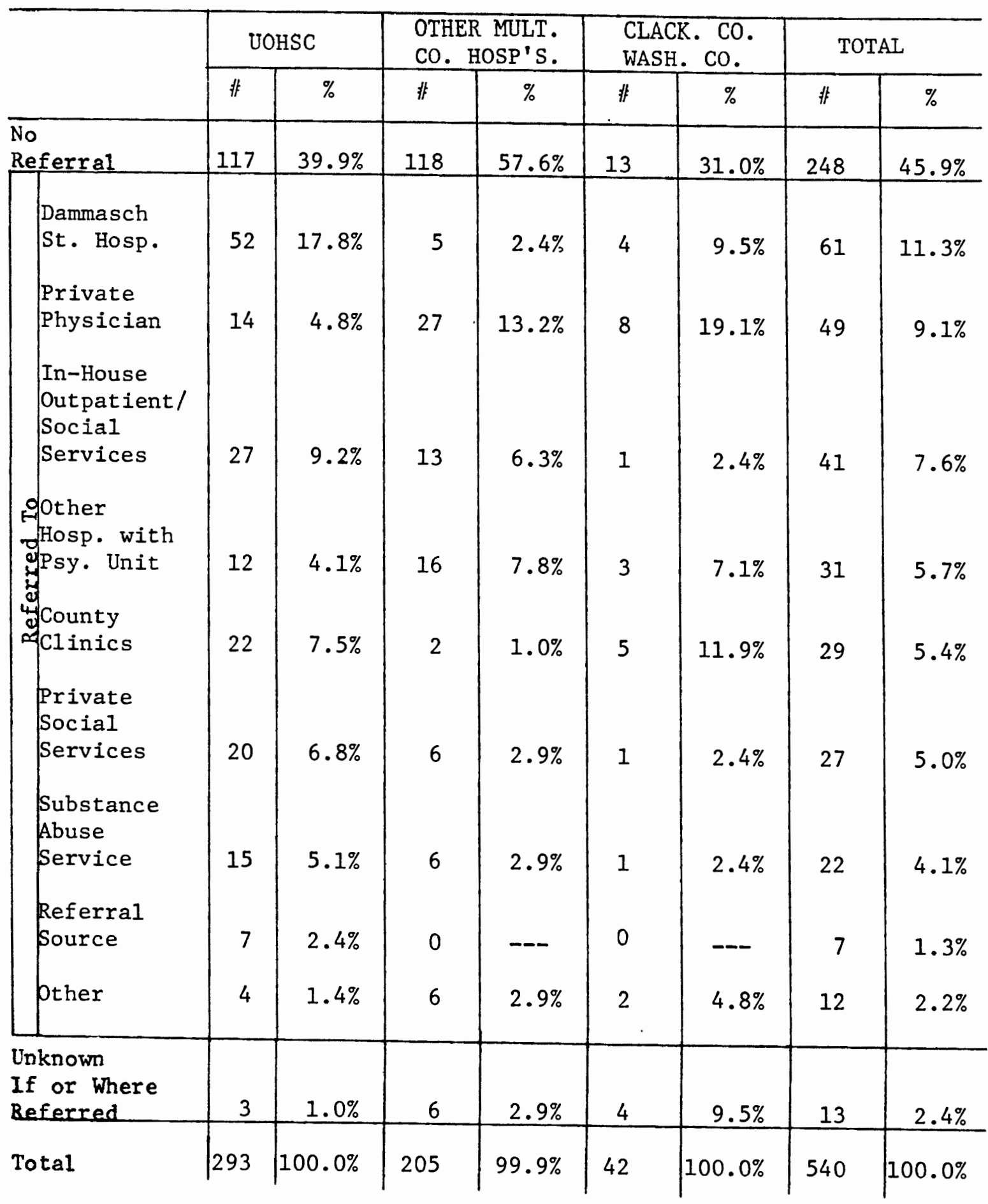


TABLE XV

SEX OE CIIENTS DETAINED ON

NOTICE OF MENTAL ILLNESS

\begin{tabular}{l|c|c}
\hline & $\#$ & $\%$ \\
\hline Male & 34 & $58.6 \%$ \\
Female & 20 & $34.5 \%$ \\
Unrecorded & 4 & $6.9 \%$ \\
\hline Total & 58 & $100.0 \%$
\end{tabular}

TABLE XVI

AGES OF CLIENTS DETAINED ON

NOTICE OF MENTAL ILLNESS

\begin{tabular}{l|c|c}
\hline & \# & $\%$ \\
\hline $0-15$ Years & 2 & $3.5 \%$ \\
$16-20$ Years & 9 & $15.5 \%$ \\
$21-35$ Years & 30 & $51.7 \%$ \\
$36-50$ Years & 9 & $15.5 \%$ \\
51 Years and Over & 4 & $6.9 \%$ \\
Unknown & 4 & $6.9 \%$ \\
\hline Total & 58 & $100.0 \%$
\end{tabular}


TABLE XVII

REFERRAL SOURCE OF CLIENTS DETAINED

ON NOTICE OF MENTAL ILLNESS

\begin{tabular}{|c|c|c|}
\hline & 非 & $\%$ \\
\hline Police & 52 & $89.7 \%$ \\
\hline Self/Family/Friends & 4 & $6.9 \%$ \\
\hline Agency & 2 & $3.5 \%$ \\
\hline Total & 58 & $100.1 \%$ \\
\hline
\end{tabular}

TABLE XVIII

DAY OF WEEK ON WHICH CLIENTS DETAINED

ON NOTICE OF MENTAL ILLNESS

\begin{tabular}{l|c|c}
\hline & $\#$ & $\%$ \\
\hline Sunday & 7 & $12.1 \%$ \\
Monday & 6 & $10.4 \%$ \\
Tuesday & 11 & $19.0 \%$ \\
Wednesday & 3 & $5.2 \%$ \\
Thursday & 9 & $15.5 \%$ \\
Friday & 11 & $19.0 \%$ \\
Saturday & 11 & $19.0 \%$ \\
\hline Total & 58 & $100.2 \%$
\end{tabular}


TABLE XIX

TIME OF DAY AT WHICH CLIENTS DETAINED

ON NOTICE OF MENTAL ILLNESS

\begin{tabular}{l|c|c}
\hline & $\#$ & $\%$ \\
\hline Midnight to 6 am & 16 & $27.6 \%$ \\
6 am to Noon & 14 & $24.1 \%$ \\
Noon to 6 pm & 9 & $15.5 \%$ \\
6 pm to Midnight & 16 & $27.5 \%$ \\
Time Unknown & 3 & $5.2 \%$ \\
\hline Total & 58 & $100.0 \%$
\end{tabular}

Final disposition. Data from "Hospitalizations" and "Referrals" was cross-tabulated to determine the final disposition of all clients studied. Hospitalization takes precedence over a referral: if a client was referred to another hospital and subsequently hospitalized, the final disposition is considered to be hospitalization. None of the clients whose final disposition was considered to be referral were known to be hospitalized. This data is presented in TABLE XX.

The data from the combined categories "Hospitalization," "Referrals," "Not Hospitalized/No Referral," and "Unknown" is presented in graphic form in Figure 4. 
TABLE XX

FINAI DISPOSITION OF ALL CIENTS STUDIED

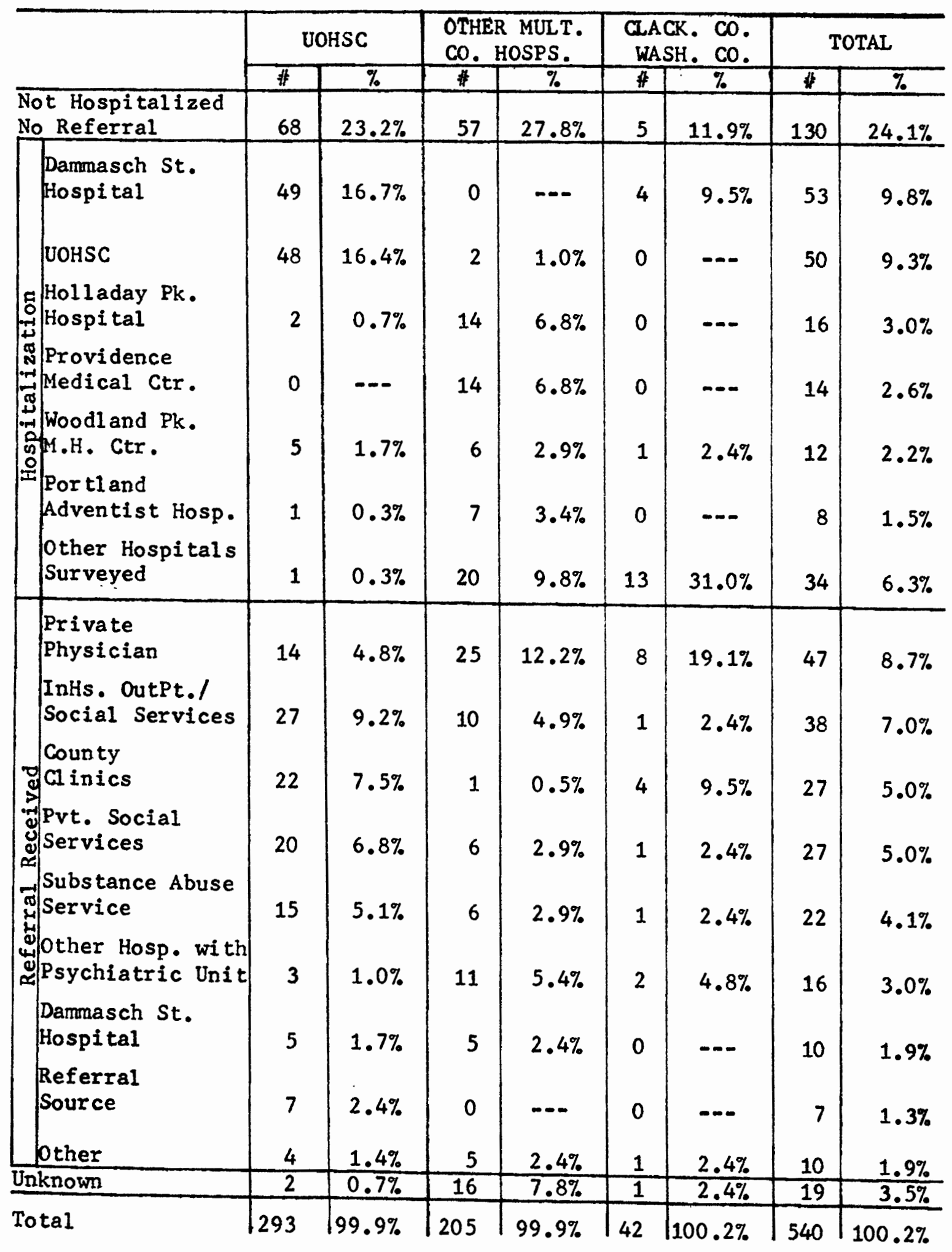




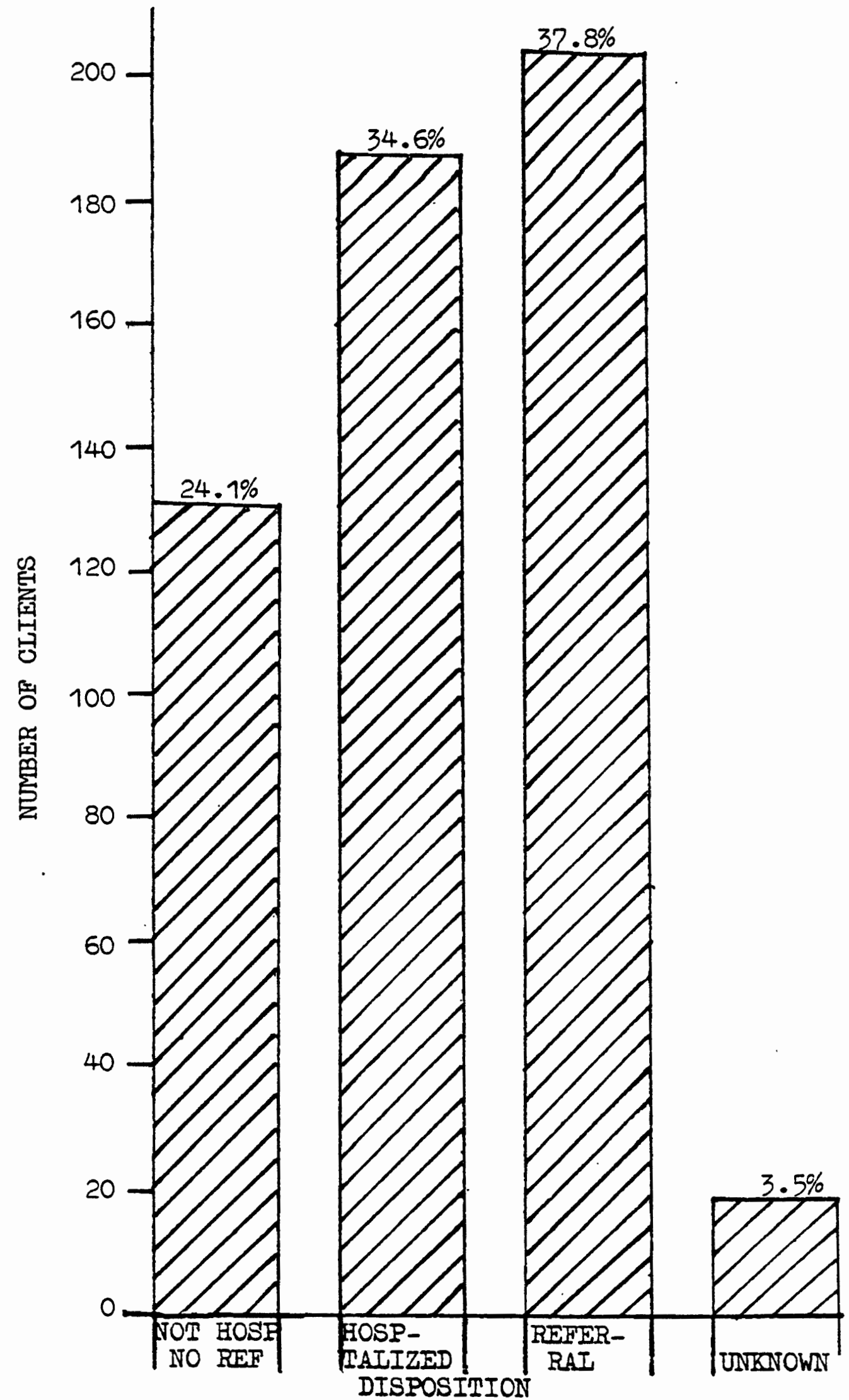

Figure 4. Final disposition of clients surveyed. 


\section{Discussion}

The course of emergency room treatment and disposition reveals that almost one half of the admissions were treated within two hours. Considering the nature and complexity of these admissions and the fact that this time frame includes a waiting period, ER staff are to be commended for their timely response in serving this population.

Clients served by UOHSC spent a longer time in the ER compared to other hospitals. This may simply reflect the higher volume of cases at that facility.

Ten percent of the entire population surveyed was involuntarily detained on a Notice of Mental Illness. Of this group, one observes a higher proportion of males, and a higher proportion of clients 21-35 years of age, almost all of whom were admitted on police holds, usually on a Friday, Saturday, or Sunday, to UOHSC. As noted in APPENDIX C, no specific information was requested from ER staff about this population, and the reader is referred to the Mul tnomah County Involuntary Comnitment Program for further data and research in this area.

Disposition of cases at UOHSC indicated a higher frequency for supportive therapy, agency referral, and psychiatric admission. The high usage and the fact that a separate psychiatric service is available in this emergency room may contribute to a staff more knowledgeable out of necessity about the delivery of mental heal th services both in the ER and in the community. The increased frequency of psychiatric admissions can be explained at least in part by the fact that all police holds are transported to this facility.

Thirty-five percent of clients for whom disposition was immediate 
hospitalization were transferred to inpatient medical units. This group is characterized as having a primary problem of a medical nature with underlying mental heal th difficulties. 


\section{CHAPTER V}

MAJOR FINDINGS:

WHAT BRINGS THESE CLIENTS TO THE ER?

The next question this study set out to answer is "What brings those clients identified as having mental heal th problems to a hospital emergency room?" There are two ways to answer this question. One way is by looking at the specific problems presented in the ER. The other way is to look at why clients choose an ER over specifically désignated mental health agencies. It is the former answer which the researchers wish to address first.

What is the Presenting Problem?

Initially, the researchers had hoped to identify how frequently the primary presenting problem was of a medical nature with an underlying (related or unrelated) mental helath problem, and how of ten the primary presenting problem was of a mental health nature.

One of the implications in collecting this kind of information lies in the possible development of a triage service to direct those clients with primary presenting problems of a mental heal th nature to appropriate mental heal th services. Another implication lies in the dirrection of supplying information to identify the need for new services or additional hours for existing services. This information was not clearly available from the responses to the question "Why did the client come to the ER?" and the need for further study is clear. 
The responses indicated a mixture of primary medical problems, primary mental heal th problems, the clients' stated reasons for coming to the ER, and the ER staff's observations of the clients' general problems: In an attempt to make some use of this mixture of information, the responses were classified into nine broad categories. These categories exhibit some degree of overlap and in many cases more than one category was needed to identify the presenting problem. Because of this, the sum of the percentages presented here is greater than 100 percent.

TABLE XXI lists the percentage of clients presenting specific problems. Approximately 18 percent of the presenting problems involved depression, anxiety, nervousness, or sleeping problems. In many of these cases, a prescription medication was requested to alleviate the problem. Seventeen percent of the cases were identified as drug and/or al cohol overdoses.*

Physical complaint, such as headaches, back pain, or dizziness, accounted for approximately 15 percent of the presenting problems, and were frequently accompanied by complaints of depression or nervousness, or requests for medications. Physical injuries (other than those resulting from identified suicide attempts) and effects of alcohol or drug use each accounted for another nine percent of the presenting problems.

*Almost 37 percent of these overdoses were identified as involving a single drug, while multiple drugs were involved in almost nine percent of the overdoses. A combination of alcohol and drugs was indicated in almost 13 percent of the overdoses. The drugs which were identified included two major tranquilizers, five barbiturate or barbiturate-like sedatives, and six non-barbiturate sedatives, as well as three narcotics, two anti-depressants, and a stimulant. The 1ist also includes an anticonvulsant, an anti-diabetic, several over-the-counter analgesics, and various unidentifled sleeping pills and "nerve" pills. The substances involved in the balance of the overdoses were unknown or not identified. 
Identified suicide attempts, and suicide ideation or threats, were involved in eight percent of the cases reported. This does not include deliberate overdoses unless they were so identified by the ER staff, so the actual percentage attributable to suicide attempts is probably somewhat higher.

Aggressive behavior was identified as the presenting problem in five percent of the reported cases. Medication problems and requests for prescriptions or prescription refills also represent five percent of presenting problems.

Abnormal and/or unusual behavior not already considered, such as hallucinations, paranoia, or confusion, were involved in approximately 11 percent of the cases reported. Other miscellaneous problems represented 19 percent. If considered individually, none of these were involved in more than approximately three percent of the cases reported.

TABLE XXI

PRESENTING PROBLEMS

Depression/Anxiety/Nervousness/Sleeping Problems ...... 18\% Drug/Al cohol overdoses ................. 17\% Physical Complaints .................. 15\% Physical Injuries .................... 9\% Alcohol/Drug Use Effects ................ 9\% Suicide Attempts/Suicide Ideation/Suicide Threats ....... $8 \%$ Aggressive Behavior .................. 5\% Medication Problems/Requests for Prescriptions or Refills/EPS . . 5\% Abnormal/Unusual Behavior ............... 11\% Miscellaneous .......................... 19\% Total $116 \%$ 
What is the Staff Diagnosis?

The answer to the question "What was identified as the client's primary mental health problem?" forms the basis for inclusion in the study population. Adnittedly, it was necessary to use the classification MEDICAI PROBLEMS in grouping the responses to this question, so: it is logical to ask why these clients were included in the study population. To answer this, it is useful to remember that the purpose of the open-ended question was to allow the ER staff to define the mental health problems they were seeing in the ER. While the responses which fell into this category did not indicate any present mental heal th problem, there were indications of past or possible future mental health involvement.

When looking at the total collection of responses to the question, substance abuse was the most frequently reported diagnosis, accounting for over one-quarter $(27.4 \%)$ of the mental health problems identified. About half of substance abuse cases were attributed to alcohol, and half were attributed to drugs.

Depression accounted for one-fifth $(20.9 \%)$ of the mental heal th problems, and psychoses for 15.9 percent of the cases. (It should be noted that psychosis is one of the least diagnostically reliable of the categories used here, as is neurosis, since most of the cases were classified as such as a result of the researchers' interpretation and categorfzation of the ER staff's description of behavior.)

Personality disorders and neuroses were the least frequently reported mental health problems (5.7\% and $5.2 \%$ respectively). See TABLE XXII. 
TABLE XXII also provides other information. Hospitals reporting from outside Multnomah County indicate that the most frequently seen diagnosis was evenly divided between substance abuse and depression (31.0\% each). Mul tnomah County hospitals report that the most frequently seen diagnosis is substance abuse $(34.2 \%)$, whether or not UOHSC is included. UOHSC reports psychosis as the most frequently seen diagnosis $(25.3 \%)$. This is consistent with the fact that UOHSC holds the county contract for holding clients detained on a Notice of Mental IIlness (police holds).

TABLE XXII

STAFF DIAGNOSIS

\begin{tabular}{|c|c|c|c|c|c|c|c|c|}
\hline \multirow[b]{2}{*}{ DIAGNOSIS } & \multicolumn{2}{|c|}{ UOHSC } & \multicolumn{2}{|c|}{$\begin{array}{l}\text { OTHER MULT. } \\
\text { CO. HOSPS. }\end{array}$} & \multicolumn{2}{|c|}{$\begin{array}{l}\text { CACK. } \mathrm{CO} . \\
\text { WASH. } \mathrm{CO} .\end{array}$} & \multicolumn{2}{|c|}{ TOTAL } \\
\hline & $\#$ & $\%$ & $\#$ & $\%$ & $\$$ & $\%$ & \# & $\%$ \\
\hline $\begin{array}{l}\text { Substance } \\
\text { Abuse }\end{array}$ & 65 & $22.2 \%$ & 70 & $34.1 \%$ & 13 & $31.0 \%$ & 148 & $27.4 \%$ \\
\hline $\begin{array}{l}\text { (A1 cohol) } \\
\text { (Drug) }\end{array}$ & $\begin{array}{l}(38) \\
(27)\end{array}$ & $\begin{array}{r}(13.6 \%) \\
(9.2 \%)\end{array}$ & $\begin{array}{l}(26) \\
(44)\end{array}$ & $\begin{array}{l}(12.7 \%) \\
(21.5 \%)\end{array}$ & $\begin{array}{l}(7) \\
(6)\end{array}$ & $\begin{array}{l}(16.7 \%) \\
(14.3 \%)\end{array}$ & $\begin{array}{l}(71) \\
(77)\end{array}$ & $\begin{array}{l}(13.2 \%) \\
(14.3 \%)\end{array}$ \\
\hline Depression & 61 & $20.8 \%$ & 39 & $19.0 \%$ & 13 & $31.0 \%$ & 113 & $20.9 \%$ \\
\hline Psychosis & 74 & $25.3 \%$ & 11 & $5.4 \%$ & 1 & $2.4 \%$ & 86 & $15.9 \%$ \\
\hline $\begin{array}{l}\text { Transient } \\
\text { Situational } \\
\text { Disturbance }\end{array}$ & 21 & $7.2 \%$ & 19 & $9.3 \%$ & 2 & $4.8 \%$ & 42 & $7.8 \%$ \\
\hline $\begin{array}{l}\text { Personal ity } \\
\text { Disorder }\end{array}$ & 26 & $8.9 \%$ & 4 & $1.9 \%$ & 1 & $2.4 \%$ & 31 & $5.7 \%$ \\
\hline Neurosis & 13 & $4.4 \%$ & 14 & $6.8 \%$ & 1 & $2.4 \%$ & 28 & $5.2 \%$ \\
\hline Medical & 7 & $2.4 \%$ & 20 & $9.8 \%$ & 1 & $2.4 \%$ & 28 & $5.2 \%$ \\
\hline Other & 26 & $8.9 \%$ & 28 & $13.7 \%$ & 10 & $23.8 \%$ & 64 & $11.9 \%$ \\
\hline Total & 293 & $100.1 \%$ & 205 & $100.0 \%$ & 42 & $99.9 \%$ & 540 & $100.0 \%$ \\
\hline
\end{tabular}

Another view of this data is from the perspective of which diagnoses were reported as the most frequently seen by individual hospitals. 
Nine out of the fifteen ERs reporting indicated that substance abuse was the most frequent mental heal th problem, with only two of these reporting alcohol abuse as more frequent than drug abuse. Five of the remaining six hospitals reported depression as the most frequent diagnosis. One hospital reported psychosis as the most frequently exhibited prob1em. See TABLE XXIII.

In TABLE XXIV, the data on diagnosis was cross-tabulated with sex to determine if there were significant differences between male and female clients. An examination of the results shows that female clients in the survey most frequently were diagnosed as suffering from depression, while male clients were most frequently found to be substance abusers. (Information in parentheses behind the diagnoses indicates the number of clients for whom sex information was unrecorded.)

A chi square test, using all categories except MEDICAL and OTHER, proved the differences significant to the .002 level.

Who Referred the Client to the ER?

As revealed by TABLE XXV, no matter how the data on referral sources is examined, the significant statement to be made is that over half of the population in this study came to the emergency room on their own or at the suggestion of family or friends $(64.8 \%$ of the total population surveyed). Twenty-one point one percent were brought in by the police, with approximately three-quarters of these clients going to UOHSC. (Again, this is consistent with the fact that UOHSC holds the county contract for police holds.) Less than eight percent of the clients studied were referred by other social services agencies. 


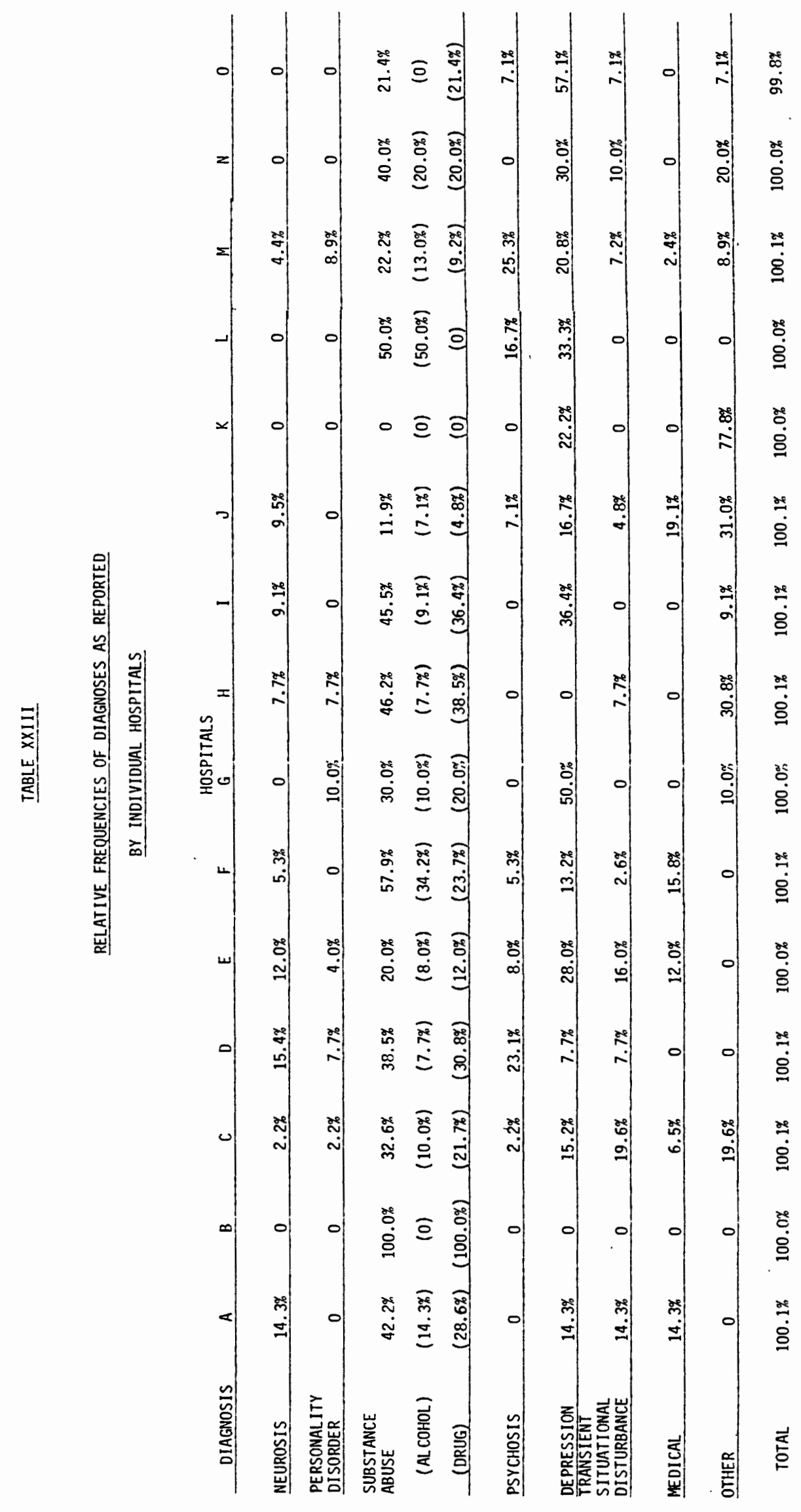


TABLE XXIV

DIAGNOSES BY SEX

\begin{tabular}{|c|c|c|c|c|c|c|}
\hline & \multicolumn{2}{|c|}{ FEMALE } & \multicolumn{2}{|c|}{ MALE } & \multicolumn{2}{|c|}{ TOTAI } \\
\hline & $\#$ & $\%$ & \# & $\%$ & \# & $\%$ \\
\hline $\begin{array}{l}\text { Substance Abuse } \\
\text { ( } 9 \text { Unrecorded*) }\end{array}$ & 54 & $19.6 \%$ & 85 & $34.6 \%$ & 148 & $27.4 \%$ \\
\hline (Alcohol) (4 Unrec.) & (18) & $(6.5 \%)$ & (49) & $(19.9 \%)$ & (71) & $(13.5 \%)$ \\
\hline (Drug) (5 Unrec.) & (36) & $(13.0 \%)$ & $(36)$ & $(14.6 \%)$ & $(77)$ & $(14.3 \%)$ \\
\hline Depression ( 1 Unrec.) & 73 & $26.5 \%$ & 39 & $15.9 \%$ & 113 & $20.9 \%$ \\
\hline Psychosis (3 Unrec.) & 44 & $16.0 \%$ & 39 & $15.9 \%$ & 86 & $15.9 \%$ \\
\hline $\begin{array}{l}\text { Transient Situational } \\
\text { Disturbance (1 Unrec.) }\end{array}$ & 29 & $10.5 \%$ & 12 & $4.9 \%$ & 42 & $7.8 \%$ \\
\hline $\begin{array}{l}\text { Personality Disorder } \\
\text { (0 Unrecorded) }\end{array}$ & 18 & $6.5 \%$ & 13 & $5.3 \%$ & 31 & $5.7 \%$ \\
\hline Neurosis ( 0 Unrec.) & 14 & $5.1 \%$ & 14 & $5.7 \%$ & 28 & $5.2 \%$ \\
\hline Medical (1 Unrec.) & 13 & $4.7 \%$ & 14 & $5.7 \%$ & 28 & $5.2 \%$ \\
\hline Other ( 3 Unrec.) & 31 & $11.2 \%$ & 30 & $12.2 \%$ & 64 & $11.9 \%$ \\
\hline Total (18 Unrec.) & 276 & $100.1 \%$ & 246 & $100.2 \%$ & 540 & $100.0 \%$ \\
\hline
\end{tabular}

* Sex of clients unrecorded; unrecorded must be added to numbers in "female" and "male" columns to get total. 


\section{TABLE XXV}

REFERRAL SOURCE

\begin{tabular}{|c|c|c|c|c|c|c|c|c|}
\hline & \multicolumn{2}{|c|}{ UOHSC } & \multicolumn{2}{|c|}{$\begin{array}{l}\text { OTHER MULT. } \\
\text { CO. HOSPS. }\end{array}$} & \multicolumn{2}{|c|}{$\begin{array}{l}\text { CLACK. CO. } \\
\text { WASH. CO. }\end{array}$} & \multicolumn{2}{|c|}{ TOTAL } \\
\hline & \# & $\%$ & \# & $\%$ & $\#$ & $\%$ & $\#$ & $\%$ \\
\hline Self/Family/Friends & 158 & $53.9 \%$ & 158 & $77.1 \%$ & 34 & $81.0 \%$ & 350 & $64.8 \%$ \\
\hline Police & 86 & $29.4 \%$ & 23 & $11.2 \%$ & 5 & $11.9 \%$ & 114 & $21.1 \%$ \\
\hline Agency & 28 & $9.6 \%$ & 11 & $5.4 \%$ & 1 & $2.4 \%$ & 40 & $7.4 \%$ \\
\hline Unknown & 21 & $7.2 \%$ & 13 & $6.3 \%$ & 2 & $4.8 \%$ & 36 & $6.7 \%$ \\
\hline Total & 293 & $100.1 \%$ & 205 & $100.0 \%$ & 42 & $100.1 \%$ & 540 & $100.0 \%$ \\
\hline
\end{tabular}

Discussion

Viewed either from the perspective of the client's presenting problem or the ER staff's diagnosis, substance abuse represents over onefourth of all ER admissions. Additionally, 60 percent of the hospitals recognize substance abuse as the most common problem.

This high incidence of reported substance abuse suggests that the inftial $E R$ attention is most 1 ikely to require a medical response rather than a psycho-therapeutic response.

In addition to diagnosis, the other descriptive response to the question of what brought the client to the ER involves information about referral sources. The data revealed that 65 percent of ER admissions represented a voluntary choice on the part of the person or family/friends. One could conclude from this that the hospital ER is publically visable and viewed as a useful resource for people in distress. 
Twenty-one percent of the admissions were accompanied by the police, which acknowledges the inextricable role of peace officers in dealing with this population. 


\section{CHAPTER VI}

MAJOR FINDINGS:

WHAT ADDITIONAL SERVICES ARE NEEDED?

Even though this is the last question to which the researchers sought an answer, it is the question which is at the heart of the entire study. If responsible planning is to take place in the mental heal th field, it is necessary to have some very specific answers to this question.

Al though this study cannot provide those specific answers, it can and does point the way for future studies.

Do Clients Need the Services of Other Agencies?

The questions "To what kind of service would you like to have referred the client?" and "Were there any unresolved treatment problems or service needs?" were probably the most frequently unanswered questions in the study. This information was not ascertainable for $173 \mathrm{clients}$ $(32.0 \%)$. The available data is presented in TABLE XXVI.

ER staff indicated that additional services beyond those provided by the ER were not needed by 220 clients $(40.7 \%)$. One hundred ninetyseven of these clients had already been hospitalized or referred to another service.

of the other 147 clients for whom information was available, 68 (12.6\%) needed immediate outpatient access, $34(6.3 \%)$ would have benefitted by outreach or crisis intervention, and $36(6.7 \%)$ needed substance abuse services. Four clients $(0.7 \%)$ required residential care, four 
needed inpatient psychiatric admission which was not received, and one required a locked security room.

TABLE XXVI

ADDITIONAL SERVICES NEEDED

\begin{tabular}{|c|c|c|c|c|c|c|c|c|}
\hline & \multicolumn{2}{|c|}{ UOHSC } & \multicolumn{2}{|c|}{$\begin{array}{l}\text { OTHER MULT. } \\
\text { CO. HOSPS. }\end{array}$} & \multicolumn{2}{|c|}{$\begin{array}{l}\text { CLACK. } \mathrm{CO} . \\
\text { WASH. } \mathrm{CO} .\end{array}$} & \multicolumn{2}{|c|}{ TOTAL } \\
\hline & \# & $\%$ & $\#$ & $\%$ & $\#$ & $\%$ & $\#$ & $\%$ \\
\hline Not Needed & 161 & $55.0 \%$ & 45 & $22.0 \%$ & 14 & $33.3 \%$ & 220 & $40.7 \%$ \\
\hline Unknown/Not & & & & & & & & \\
\hline Ascertainable & 91 & $31.1 \%$ & 69 & $33.7 \%$ & 13 & $31.0 \%$ & 173 & $32.0 \%$ \\
\hline Immediate outpt. & & & & & & & & \\
\hline Access & 23 & $7,9 \%$ & 37 & $18.1 \%$ & 8 & $19.1 \%$ & 68 & $12.6 \%$ \\
\hline Substance Abuse & & & & & & & & \\
\hline Service & 5 & $1.7 \%$ & 29 & $14.2 \%$ & 2 & $4.8 \%$ & 36 & $6.7 \%$ \\
\hline Outreach/Crisis & & & & & & & & \\
\hline Intervention & 11 & $3.8 \%$ & 19 & $9.3 \%$ & 4 & $9.5 \%$ & 34 & $6.3 \%$ \\
\hline Psychiatric & & & & & & & & \\
\hline Admission & 0 & $-\infty$ & 4 & $2.0 \%$ & 0 & $-\infty$ & 4 & $0.7 \%$ \\
\hline Residential Care & 2 & $0.7 \%$ & 2 & $1.0 \%$ & 0 & $--\infty$ & 4 & $0.7 \%$ \\
\hline Locked Security & & & & & & & & \\
\hline Room & 0 & $-\infty$ & 0 & --- & 1 & $2.4 \%$ & 1 & $0.2 \%$ \\
\hline Total & 293 & $100.2 \%$ & 205 & $100.3 \%$ & 42 & $100.1 \%$ & 540 & $99.9 \%$ \\
\hline
\end{tabular}

In comparing the number of $c 1$ ients needing additional services reported by UOHCS to those reported by all other hospitals surveyed, the differences proved significant to the .002 level . UOHSC reported a significantly higher proportion of clients not needing additional services, and the other hospitals showed significantly higher proportion of clients needing additional services. 
Do Cients Need Transportation?

The need for transportation services from ERs to other agencies was expected to be great. The availability of transportation for such purposes was expected to be low. In actuality, hospital ER staff reported the opposite in both cases, as shown by TABLES XXVII, XXVIII, and XXIX.

Transportation was needed for 28.2 percent of the clients (152). Three hundred fifty-three clients (65.4\%) did not need transportation, and the need for transportation was unknown in $35(6.5 \%)$ of the cases.

TABLE XXVII

NEED FOR TRANSPORTATION

\begin{tabular}{|c|c|c|c|c|c|c|c|c|}
\hline & \multicolumn{2}{|c|}{ UOHSC } & \multicolumn{2}{|c|}{$\begin{array}{l}\text { OTHER MULT. } \\
\text { CO. HOSPS. }\end{array}$} & \multicolumn{2}{|c|}{$\begin{array}{l}\text { CLACK. CO. } \\
\text { WASH. CO. }\end{array}$} & \multicolumn{2}{|c|}{ TOTAL } \\
\hline & $\#$ & $\%$ & $\#$ & $\%$ & $\#$ & $\%$ & \# & $\%$ \\
\hline Not Needed & 173 & $59.0 \%$ & 154 & $75.1 \%$ & 26 & $61.9 \%$ & 353 & $65.4 \%$ \\
\hline Needed & 110 & $37.5 \%$ & 30 & $14.6 \%$ & 12 & $28.6 \%$ & 152 & $28.2 \%$ \\
\hline Unknown & 10 & $3.4 \%$ & 21 & $10.2 \%$ & 4 & $9.5 \%$ & 35 & $6.5 \%$ \\
\hline Total & 293 & $99.9 \%$ & 205 & $99.9 \%$ & 42 & $100.0 \%$ & 540 & $100.1 \%$ \\
\hline
\end{tabular}

Transportation was available for 60.4 percent (326) of the clients studied. One hundred twenty clients $(22.2 \%)$ did not hav transportation available, and it was unknown whether the remaining 94 clients $(17.4 \%)$ had transportation available.

The need for and availability of transportation was cross-tabulated to produce more specific information. In only 25 cases out of 540 (4.6\%) was transportation needed and not available. 
TABLE XXVIII

AVAILABILITY OF TRANSPORTATION

\begin{tabular}{|c|c|c|c|c|c|c|c|c|}
\hline & \multicolumn{2}{|c|}{ UOHSC } & \multicolumn{2}{|c|}{$\begin{array}{l}\text { OTHER MULT. } \\
\text { CO. HOSPS. }\end{array}$} & \multicolumn{2}{|c|}{$\begin{array}{l}\text { CLACK. } \mathrm{CO} \text {. } \\
\text { WASH. } \mathrm{CO} . \\
\end{array}$} & \multicolumn{2}{|c|}{ TOTAL } \\
\hline & 非 & $\%$ & \# & $\%$ & 非 & $\%$ & 非 & $\%$ \\
\hline Available & 184 & $62.8 \%$ & 115 & $56.1 \%$ & 27 & $64.3 \%$ & 326 & $60.4 \%$ \\
\hline Not available & 81 & $27.7 \%$ & 35 & $17.1 \%$ & 4 & $9.5 \%$ & 120 & $22.2 \%$ \\
\hline Unknown & 28 & $9.6 \%$ & 55 & $26.8 \%$ & 11 & $26.2 \%$ & 94 & $17.4 \%$ \\
\hline Tota1 & 293 & $100.1 \%$ & 205 & $100.0 \%$ & 42 & $100.0 \%$ & 540 & $100.0 \%$ \\
\hline
\end{tabular}

TABLE XXIX

TRANSPORTATION NEEDED BUT NOT AVAILABLE

\begin{tabular}{c|c|c|c|c|c|c|c|c}
\hline & \multicolumn{2}{|c|}{ UOHSC } & \multicolumn{2}{c|}{$\begin{array}{c}\text { OTHER MULT. } \\
\text { CO. HOSPS. }\end{array}$} & $\begin{array}{c}\text { CLACK. CO. } \\
\text { WASH. CO. }\end{array}$ & \multicolumn{2}{c|}{ TOTAL } \\
\cline { 2 - 8 } & \#\# & $\%$ & $\#$ & $\%$ & $\#$ & $\%$ & $\#$ & $\%$ \\
\hline $\begin{array}{c}\text { Needed/Not } \\
\text { Availab1e }\end{array}$ & 21 & $\begin{array}{c}7.2 \% \\
\text { of } 293\end{array}$ & 4 & $\begin{array}{c}2.0 \% \\
\text { of } 205\end{array}$ & 0 & $-\cdots$ & 25 & $\begin{array}{c}4.6 \% \\
\text { of } 540\end{array}$
\end{tabular}

\section{Additional Information}

The final item on the survey form was a request for additional comments. Approximately 14 percent of the survey forms contained statements which were not directly related to questions in the body of the survey, but which serve to 111 ustrate additional problems encountered in dealing with clients with mental heal th problems. Those most frequently reported are included here for consideration by the reader.

The lack of cooperation exhibited by many clients with mental heal th problems was the most frequent complaint of the ER staff. This 
included the refusal of treatment, a lack of follow-through on referrals and other types of recommended treatment, and the identification of specific clients as frequent users of the ER.

ER staff indicated that clients were experiencing some difficulty in obtaining appointments at county mental heal th clinics. Other staff indicated that clients were being treated within the ER almost exclusively for physical symptoms, and some complained that the drugs being abused by the clients were being prescribed by the clients' own doctors.

Discussion

Thirty-two percent of the returned questionnaires did not contain an answer to questions which dealt with what additional services are needed. UOHSC emergency room staff recorded less of a need for additional services than did other hospital ERs. Several explanations may be posed: (a) the high volume of cases which realistically impinges on the time available to record information; (b) UOHSC's high referral rate to their own outpatient service; and (c) the staff's familiarity with and use of local commity mental health resources.

Much to the surprise of the researchers, the issue of transportation was not recognized as a service gap in 95 percent of the cases. This may indicate that the existing network (family, friend, bus, taxi, ambulance, police) is sufficient.

Finally, the questionnaire gave the respondents an opportunity to make any additional coments. Only 14 percent did so, again, perhaps reflecting the time constraints of ER duty. 


\section{CHAPTER VII}

MAJOR FINDINGS:

REASONABLE vS. QUESTIONABLE USE OF THE ER

In attempting to answer the broader question of why clients identified as having mental heal th problems choose an ER rather than a mental heal th agency, the researchers had expected to be able to identify those clients with a primary medical problem and underlying mental heal th problems, who would be reasonable user of an ER at least to the extent that they did need medical support services. The balance of the clients would then be those with primarily a mental heal th problem, who might be alternatively served in other than a hospital setting (mental heal th agency, clinic, etc.).

However, for reasons already stated, it was not possible to make this distinction from the data reported. The researchers decided to approach the question from another angle--that is, by looking at the treatment received as an indication of whether the client really needed the services of a hospital ER.

Several categories were identified as reasonable ER usage. These were: psychiatric admission; medical attention (which included medical hospitalization); and those clients with medical problems and no present mental health involvement, even though not all these clients received medical attention. In addition, clients brought in by the police were added to the subgroup labelled as "reasonable usage." This included all those clients detained on a Notice of Mental Illness. This process 
yielded a subgroup of 332 "reasonable users."

Those clients not falling into one of the above categories were identified as "questionable users." This subgroup consisted of 208 clients.

The reader is cautioned at this point that the definition of who is and who is not using an ER reasonably is entirely the researchers'. The crudeness of the definition, coupled with the informality and openendedness with which the study was administered, makes drawing any definite conclusions about these two subgroups unreliable. Nevertheless, the researchers felt that, as part of an initial attempt to gather descriptive information in the area of mental heal th ER users, the inclusion of a comparison of these two subgroups was valid.

An examination of the data for the subgroups "reasonable users" and "questionable users" revealed very little substantial difference between the two subgroups. However, the chi square test of association (or statistical independence) was applied to a number of categories to verify this. Categories which were subjected to the chi square test were: day of week and time of day admitted; length of stay; age; sex; address; insurance coverage; diagnosis; referral received; and services needed.

In those categories where the unrecorded responses were too great to be distributed within the category, they were not included in the chi square test. In general, the unrecorded responses represented approximately the same proportion of items in the questionable users as in the reasonable user subgroup for most of the categories examined. Since their inclusion could have an unknown influence on the chi square test 
which could not be attributed to the "reasonableness" variable, it was felt that calculations based only on actual information available would give a more reliable test, even though it would impose limitations on the results.

The results of the chi square tests showed a significant difference in the distribution of data between the two subgroups in only five categories.

Insurance coverage. Differences in reported insurance or other third-party resources, shown in TABLE XXX, were significant to the .05 level. "No insurance coverage" was associated most closely with questionable use, and "other third-party coverage" wi th reasonable use.

TABLE XXX

COMPARISON OF INSURANCE COVERAGE:

REASONABLE vS. QUESTIONABLE USAGE

\begin{tabular}{l|c|c|c|c}
\hline & \multicolumn{2}{|c|}{ REASONABLE USERS } & \multicolumn{2}{c}{ QUESTIONABLE USERS } \\
\cline { 2 - 5 } & $\#$ & $\%$ & $\#$ & $\%$ \\
\hline Insurance & 86 & $25.9 \%$ & 47 & $22.6 \%$ \\
Other Third Party & 102 & $30.7 \%$ & 49 & $23.6 \%$ \\
None & 85 & $25.6 \%$ & 75 & $36.1 \%$ \\
Unknown & 59 & $17.8 \%$ & 37 & $17.8 \%$ \\
\hline Total & 332 & $100.0 \%$ & 208 & $100.1 \%$
\end{tabular}

Additional services needed. This category was compared between the two subgroups on the basis of whether they were needed or not as presented in TABLE XXXI. Chi square tests showed the differences signifi- 
cant to the $.051 \mathrm{evel}$. The direction of this difference was predictable since 56 percent of the reasonable users subgroup was hospitalized and would not have been in need of additional services.

The unrecorded responses in this category differed greatly (26.8\% for reasonable users and $40.4 \%$ for questionable users). This was not surprising in view of the fact that ER staff are not always trained to diagnose and refer clients with mental health probleans. It may, however, have had an effect on the outcome of the chi square test.

\section{TABLE XXXI}

COMPARISON OF ADDITIONAL SERVICES NEEDED:

REASONABLE vS. QUESTIONABLE USAGE

\begin{tabular}{l|c|c|c|c}
\hline \multirow{2}{*}{} & \multicolumn{2}{|c|}{ REASONABLE USERS } & \multicolumn{2}{c}{ QUESTIONABLE USERS } \\
\cline { 2 - 5 } & \# & $\%$ & $\ldots$ & $\%$ \\
\hline \multirow{2}{*}{ Nes } & 88 & $26.5 \%$ & 59 & $28.4 \%$ \\
Unknown & 155 & $46.7 \%$ & 65 & $31.3 \%$ \\
& 89 & $26.8 \%$ & 84 & $40.4 \%$ \\
Total & 332 & $100.0 \%$ & 208 & $100.1 \%$
\end{tabular}

Age. The chi square test revealed that age was significant to the .02 level. This data is presented in TABLE XXXII. The age group 36-50 was most closely associated with reasonable users, and the age group 2135 was most closely associated with questionable users. 


\section{TABLE XXXII}

COMPARISON OF AGE:

REASONABLE vS. QUESTIONABLE USAGE

\begin{tabular}{|c|c|c|c|c|}
\hline & \multicolumn{2}{|c|}{ REASONABLE USERS } & \multicolumn{2}{|c|}{ QUESTIONABLE USERS } \\
\hline & \# & $\%$ & \# & $\%$ \\
\hline $0-15$ Years & 18 & $5.4 \%$ & 5 & $2.4 \%$ \\
\hline 16-20 Years & 38 & $11.5 \%$ & 28 & $13.5 \%$ \\
\hline 21-35 Years & 158 & $47.6 \%$ & 127 & $61.1 \%$ \\
\hline $36-50$ Years & 77 & $23.2 \%$ & 28 & $13.5 \%$ \\
\hline 51 Years and Older & 41 & $12.3 \%$ & 20 & $9.6 \%$ \\
\hline Total & 332 & $100.0 \%$ & 208 & $100.1 \%$ \\
\hline
\end{tabular}

Staff diagnosis. When applying the chi square test to the diagnosis category, the "medical problens" item was not included since it was one of the items used in identifying the reasonable users and questionable users subgroups. (It is included in the side-by-side comparison presented in TABLE XXXIII.) In this category the differences were found to be significant to the .002 level. Depression was most closely associated with reasonable usage, and neurosis with questionable usage. 


\section{TABLE XXXIII}

COMPARISON OF STAFF DIAGNOSES:

REASONABLE vS. QUESTIONABLE USAGE

\begin{tabular}{|c|c|c|c|c|}
\hline & \multicolumn{2}{|c|}{ REASONABLE USERS } & \multicolumn{2}{|c|}{ QUESTIONABLE USERS } \\
\hline & $\#$ & $\%$ & $\#$ & $\%$ \\
\hline Substance Abuse & 91 & $27.4 \%$ & 57 & $27.4 \%$ \\
\hline (Alcohol) & $(41)$ & $(12.3 \%)$ & $(30)$ & $(14.4 \%)$ \\
\hline (Drug) & $(50)$ & $(15.1 \%)$ & $(27)$ & $(13.0 \%)$ \\
\hline Depression & 75 & $22.6 \%$ & 38 & $18.3 \%$ \\
\hline Psychosis & 51 & $15.4 \%$ & 35 & $16.8 \%$ \\
\hline Transient Situational Disturb. & 25 & $7.5 \%$ & 17 & $8.2 \%$ \\
\hline Personality Disorder & 11 & $3.3 \%$ & 20 & $9.6 \%$ \\
\hline Neurosis & 7 & $2.1 \%$ & 21 & $10.1 \%$ \\
\hline Medical * & 28 & $8.4 \%$ & 0 & -- \\
\hline Other & 44 & $13.3 \%$ & 20 & $9.6 \%$ \\
\hline Total & 332 & $100.0 \%$ & 208 & $100.0 \%$ \\
\hline
\end{tabular}

*One of the characteristics used to define "reasonable users."

Referrals. The differences between subgroups in the "referral received" category, presented in TABLE XXXIV, were significant to the .001 1evel. Again, the direction of the differences was expected. 
TABLE XXXIV

COMPARISON OF REFERRALS RECEIVED:

REASONABLE vS. QUESTIONABLE USAGE

\begin{tabular}{l|c|c|c|c}
\hline \multirow{2}{*}{} & \multicolumn{2}{|c|}{ REASONABLE USERS } & \multicolumn{2}{c}{ QUESTIONABLE USERS } \\
\cline { 2 - 5 } & \# & $\%$ & \# & $\%$ \\
\hline Yes & 146 & $44.0 \%$ & 140 & $67.3 \%$ \\
No & 186 & $56.0 \%$ & 68 & $32.7 \%$ \\
\hline \multirow{2}{*}{ Tota1 } & 332 & $100.0 \%$ & 208 & $100.0 \%$
\end{tabular}

Discussion

In addressing the issue of whether clients facing mental health problems are more appropriately served by an emergency room, some additional information outside the scope of this study is helpful.

The very nature of an emergency room (1.e. Its 24 -hour accessibility and its non-discriminate, palliative service) in and of itself encourages a broad, high-volume usage pattern.

Between 1940 and 1955, emergency room visits in the U.S. increased over 400 percent, with no corresponding population increase*. Such increased use of emergency rooms raises the question of whether these visits represent true emergencies. In an analysis of over 200 hospital re-

*Jules V. Coleman, M.D., and Paul Errera, M.D., "The General Hospital: The Emergency Room and its Psychiatric Problems," American Journal of Public Heal th 51 (August 1963): 1, 294-301. 
cords, it was found that 42 percent of all visits were of a non-emergent nature. *

Al though the design of this survey was not intended to substantiate such an assertion, an interpretive definition of "reasonable" and "questionable" ER usage was attempted by examining the type of treatment received in the ER. In so doing, it was found that clients' use of an ER could be seriously questioned in 38 percent of the cases reported. This interpretation raises some difficult cost-effectiveness and programmatic issues:

1. Recognizing (a) that this population behaviorally acknowledges the viability and helpfulness of an ER; (b) the ER is an integral part of the heal th care delivery system; and (c) that it is accessible 24 hours a day; is it an issue worthy of addressing in the first place? If so, then:

2. Should a triage service be developed to direct clients with less emergent needs to a facility other than an ER?

3. Is the questionable use of an ER a reflection of the need for public education or a reflection of the inaccessibility of other more appropriate services (outpatient clinics and mental health agencies)?

4. Recognizing the sizable volume of clients who do not require the medical support of an ER, should hospital ER staff be trained to deliver social services?

5. Should 24-hour outpatient clinics with less expensive overhead than an ER be available to this population facing mental health problems? 


\section{CHAPTER VIII}

\section{LITERATURE REVIEW}

There has been a great deal witten on the subject of emergency psychiatric services in recent years and much of the literature deals with emergency psychiatric services received in the general hospital energency room: : Three local studies on emergency rooms and emergency services in the past two years--Talley, 1977; Hersrud, Kiser, and Knox, 1977; and Parker, 1978--have reviewed this 1iterature extensively. It seems more worthwhile, therefore, to review here the three local studies, their conclusions, and their concurrence with the present study.

Talley, Sandra Lee, Patients Use of Psychiatric Services in a University Hospital Emergency Room, 1977, University of Oregon School of Nursing. Talley's research is a descriptive study of care provided to psychiatric patients in the UOHSC emergency room over a five-month period. The study included 1,478 patients and focused on three aspects of psychiatric care: 1) the service utiliaation patterns of the emergency room and commonly used referral sources; 2) the characteristics of the psychiatric population; and 3) the process of delivering care to patients with psychiatric problems in an emergency room setting. (pp. 1415)

As previously noted, this hospital emergency room sees the greatest number of psychiatric emergency patients of any hospital in the area. Talley identifies several possible reasons for the size of the caseload, including a county contract for all police emergency court holds, and 
the previous status of county hospital providing care to the indigent. (pp. 16-17)

The billing sheets of all clients requesting psychiatric help or whose diagnosis included traditional psychiatric disorders or psychological terminology were used as the source of data on the three areas of focus. (pp. 17-18) For a random sample of 40 cases out of 261 seen during the last month of the study, complete hospital records were reviewed to provide additional data not available from the billing sheets.

Hersrud, Maren L.; Kiser, Karalee; and Knox, Catherine M.; Psychiatric Emergency Services in Oregon, 1977, Portland State University School of Social Work.

The purpose of the Hersrud, et al., study is to describe the delivery of psychiatric emergency services in selected Oregon counties, to identify variables that determine the nature of psychiatric emergency services provided, and to develop recommendations for existing psychiatric emergency services. ( p. 92)

After preliminary interviews with mental health planners, program directors, and others who had conducted research on psychiatric emergency services in Oregon, and after reading county mental health plans, the researchers developed a non-experimental descriptive field study to explore in more detail areas they identified as in need of further study. The study design provides a description of psychiatric emergency services offered by a selection of agencies and the characteristics of people who used the services in five selected counties. The design also includes a compilation of opinions held by direct service providers about the effectiveness of the psychiatric emergency service system. (pp. 94-97) 
Mul tnomah County was selected for the study because it is the most populous and most urbanized county in the state and because of its multiplicity of psychiatric emergency services. (p. 101) The descriptions of the delivery of spychiatric emergency services and client characteristics in Multnomah County, particulariy in three general hospitals-UOHSC, Providence, and Good Samaritan--are relevant to the current study.

The client data sheet was developed to gather demographic and diagnostic data and information on the types of services received, and disposition and referral data. The data was gathered by pulling the desired information from client charts. (p. 119) The researchers selected for review a random sample of charts for clients who received service during a three-month period. (p. 120)

Parker, Anne K., A Descriptive Study of Social Service Needs and Demographic Characteristics of Selected Emergency Room Patients, 1978, Portland State University School of Social Work.

Parker's study focused on the social service needs and demographic characteristics of patients admitted to Providence Hospital's energency room during the hours a social worker was not available (11 pm to 7 am, seven nights a week, and 7 am to $3 \mathrm{pm}$, Saturday and Sunday). The target population in this study has a much broader base than the current study or the two previously mentioned studies in that Parker was interested in the social service needs of all emergency room clients as opposed to those of clients receiving emergency psychiatric care. (pp. 2-4)

Because of the difference in focus, Parker took a random sample of all patients admitted to the ER; patients receiving emergency psychiatric care were not addressed separately. Thus, relevant data is not 
available for direct comparison here.

\section{Comparison of Findings}

This comparison of findings between the current study and the Talley and Hersrud, et al., studies is organized in the same manner as the major findings of the current study. Where possible data will be compared item by item. It may be necessary to telescope categories used in one study or another in order to make the comparisons. Although data is available from the current study which would allow a comparison of data on Providence and Good Samaritan Hospitals, most of this data is not presented in the major findings and so will not be presented here. Except in the case of time-of-day comparisons, data from the current study which is used in this section is available in the major findings.

\section{Who Are These Clients?}

Address. Hersrud et al. found that $71 \%$ of the clients receiving emergency psychiatric services in the Multnomah County agencies studied (including hospitals, mental heal th clinics, hot lines, and police) were residents of the county. The current study found that $68 \%$ of the clients admitted to Mul tnomah County general hospital emergency rooms resided whin the County. Fifteen and 13\% of the clients resided out of county in Hersrud and the current study respectively. In both studies there was a large number of clients for whom an address was unavailables14\% in the Hersrud study and 19\% in the current study. (Hersrud, Table $X$, p. 153) Al though it is not possible to determine what portion of this percentage is the result of an inadvertent omission, it is possible 
to speculate that a large proportion of these clients do not have a permanent address. Al though the researcher has no documentation to support this, it is commonly assumed, at least at the administrative level in mental health circles, that Mul tnomah County is a refuge for large numbers of transients. This can be explained, in part, by the anonymity offered by the highly populated, highly urbanized area; by the diversity of services offered for the indigent; and by the relatively highty developed service delivery system aimed specifically at the transient population.

It is unclear from Talley's presentation whether she found any transients among the study population. She did find that $89 \%$ of the patients in the study were Multnomah County residents, while another $7 \%$ 1ived in one or the other of two adjacent counties. The remaining $4 \%$ are simply listed as "other." (Table 5, p. 26) Comparative figures for the UOHSC portion of the current study are 61\% Mul tnomah County residents, 11\% adjacent-county residents, $5 \%$ residents outside the tri-county area, and $24 \%$ unknown.

Age. Hersrud et al. do not provide age data on the clients seen in Mul tnomah County agencies. It was necessary to combine categories in both Talley and the current study to get comparable age categories. The results are shown in Table XXXV.

The single largest actual age group in the current study for UOHSC is 21-35 years of age (see Table III); in the Talley study it is 20-29. (Table 5, p. 26) Hersrud's data, for all five counties studied, was similar, with $67 \%$ of the clients falling between the ages of 20 and 50 , and the single largest age group between 20 and 29. (Table VII, p. 149) 
TABLE XXXV

COMPARISON OF AGE DATA:

CURRENT STUDY V. TAILEY STUDY

\begin{tabular}{l|c|c|c|c}
\hline $\begin{array}{c}\text { Approximate } \\
\text { Age Groups }\end{array}$ & \multicolumn{2}{|c|}{ CURRENT STUDY-UOHSC } & \multicolumn{2}{|c}{ TALLEY STUDY-UOHSC } \\
\cline { 2 - 5 } $0-20$ years & $\%$ & $\%$ & $\%$ & $\%$ \\
$20-50$ years & 43 & $15 \%$ & 151 & $10 \%$ \\
50 and over & 223 & $76 \%$ & 1142 & $77 \%$ \\
\hline Total & 27 & $9 \%$ & 189 & $13 \%$ \\
\hline
\end{tabular}

Sex. As Table XXXVI shows, the percentages of males and females

found in the three study populations are very similar. However, Talley's study was the only one to find more males than females. (Hersrud, Table LI, p. 278; Talley, Table 5, p. 26)

TABLE XXXVI

COMPARISON OF NUMBER OF MALES AND FEMALES

IN THE THREE STUDIES

\begin{tabular}{|c|c|c|c|c|c|c|c|c|}
\hline & \multirow{2}{*}{\multicolumn{2}{|c|}{$\frac{\text { HERSRUD STUDY }}{\text { MULT. CO. }}$}} & \multicolumn{4}{|c|}{ CURRENT STUDY } & \multirow{2}{*}{\multicolumn{2}{|c|}{$\frac{\text { TALLEY STUDY }}{\text { UOHSC }}$}} \\
\hline & & & MULT & Co. & & & & \\
\hline & 4 & $\%$ & 4 & $\%$ & 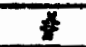 & $\%$ & 4 & $\%$ \\
\hline Male & 28 & $43 \%$ & 237 & $48 \%$ & 139 & $47 \%$ & 838 & $56 \%$ \\
\hline Female & 38 & $58 \%$ & 261 & $52 \%$ & 154 & $53 \%$ & 645 & $44 \%$ \\
\hline Total & 66 & $101 \%$ & 498 & $100 \%$ & 293 & $100 \%$ & 1483 & $100 \%$ \\
\hline
\end{tabular}

To Which Hospitals Are Clients Going?

The Talley and Hersrud studies reported on three of the fifteen hospitals surveyed in the current study. These are Providence, Good Samaritan, and UOHSC. The comparative data is presented in Table XXXVII. 
TABLE XXXVII

NUMBER OF CLIENTS RECEIVING

EMERGENCY PSYCHIATRIC SERVICES

\begin{tabular}{l|c|c|c}
\hline & HERSRUD STUDY* & CURRENT STUDY & TALLEY STUDY $* \frac{2}{4}$ \\
\hline UOHSC & 250 & 293 & 296 \\
Pnovidence & 35 & 42 & - \\
Good Samaritan & 30 & 13 & -
\end{tabular}

*Hersrud's data is based on estimates made by the hospital emergency rooms. (pp. 139-141)

**The figure for the Talley study is an average over the five months of the study. The number ranged from a low of 261 to a high of 312 . (Table 1, p. 20)

Proportion of psychiatric emergency clients. Talley includes data which places the number of psychiatric emergency clients being admitted to hospital emergency rooms into perspective. Since the number of clients in the UOHSC subpopulation of the current study (293 counted over a one-month period) is well within the range of the number of clients counted per month in the Talley study (261 to 312 ), her data has relevance to the current study.

Her findings indicate that emergency psychiatric clients make up approximately $11 \%$ of the clients admitted to the UOHSC emergency room. (Table 1, p. 20) This type of data is not available for other hospital emergency rooms. Various factors, discussed previously, which make UOHSC the most highly-used facility for psychiatric emergencies would suggest that this percentage is not generally applicable to all hospital emergency rooms. 
When Are These Gients Being Seen?

Dey of the week. Data categories from both the current study and the Talley study were combined to conform to the arrangement presented by Hersrud et al. As Table XXXVIII shows, hospital emergency rooms are seeing approximately the same number of clients with psychiatric emergencies each day of the week. Weekdays average 13-14\% of the clients per day, and week-ends average 15-16\% of the clients per day. (Hersrud, Table XI, p. 154; Talley, Table 1, p. 20)

\section{TABLE XXXVIII}

NUMBER OF CIIENTS SEEN

ON WEEK-ENDS AND WEEKDAYS

\begin{tabular}{|c|c|c|c|c|c|c|c|c|}
\hline \multirow{3}{*}{$\vdots$} & \multirow{2}{*}{\multicolumn{2}{|c|}{$\begin{array}{l}\text { HERSRUD STUDY } \\
\text { GEN. HOSP'S. }\end{array}$}} & \multicolumn{4}{|c|}{ CURRENT STUDY } & \multirow{2}{*}{\multicolumn{2}{|c|}{$\frac{\text { TALLEY STUDY }}{\text { JOHSC }}$}} \\
\hline & & & MUI & $\mathrm{CO}$ & & & & \\
\hline & 1 & $\%$ & 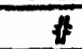 & $\%$ & $\#$ & $\%$ & \# & $\%$ \\
\hline $\begin{array}{l}\text { Week-ends } \\
(F-S-S)\end{array}$ & 45 & $48 \%$ & 229 & $46 \%$ & 137 & $47 \%$ & 645 & $44 \%$ \\
\hline $\begin{array}{l}\text { Weekdays } \\
(M-T-W-T)\end{array}$ & 48 & $52 \%$ & 269 & $54 \%$ & 156 & $53 \%$ & 833 & $56 \%$ \\
\hline Total & 93 & $100 \%$ & 498 & $100 \%$ & 293 & $100 \%$ & 1478 & $100 \%$ \\
\hline
\end{tabular}

Time of day. Because the categories used in the current study for examining the time of day at which clients were admitted to the ER were not comparable to those used in the Talley and Hersrud studies, the data was retabulated. The categories used here conform to those used by Hersrud. Talley's differ slightly, as can be seen by the items in parentheses in Table XXXIX. (Hersrud, Table XII, p. 155; Talley, Table 2, p. 22)

Hersrud found that the largest percentage of clients came into general hospital ERs between midnight and $8 \mathrm{am}$. In Talley's study the larg- 
est percentage of patients were admitted between noon and $5 \mathrm{pm}$. She found, in this five-hour period almost as large a percentage as Hersrud et al. found in the nine-hour period from 8 am to $5 \mathrm{pm}$. The current study found the largest percentage of clients--for both voHSC and all of Mul tnomah County--between the hours of $5 \mathrm{pm}$ and midnight. Low percentage periods were similarly inconsistent from one study to the next.

\section{TABLE XXXIX}

\section{TIME OF DAY CLIENTS WERE ADMITTED}

\begin{tabular}{|c|c|c|c|c|c|c|c|c|}
\hline \multirow[b]{3}{*}{ TIME OF DAY } & \multirow{2}{*}{\multicolumn{2}{|c|}{$\begin{array}{l}\text { HERSRUD STUDY } \\
\text { GEN. HOSP'S. }\end{array}$}} & \multicolumn{4}{|c|}{ CURRENT STUDY } & \multirow{2}{*}{\multicolumn{2}{|c|}{$\frac{\text { TALLEY STUDY }}{\text { UOHSC }}$}} \\
\hline & & & \multicolumn{2}{|c|}{ MULT. $\mathrm{CO.*}$} & \multicolumn{2}{|c|}{ UOHSC* } & & \\
\hline & 4 & 7 & $\$$ & $\%$ & 4 & $\%$ & 4 & 7 \\
\hline $\begin{array}{l}\text { Midnight to } 8 \text { am } \\
\text { (11 pm to } 8 \mathrm{am})\end{array}$ & 42 & $45 \%$ & 119 & $24 \%$ & 57 & $20 \%$ & 218 & $15 \%$ \\
\hline (8 am to Noon) & 33 & $35 \%$ & 65 & $13 \%$ & 43 & $15 \%$ & 453 & $31 \%$ \\
\hline (Noon to $5 \mathrm{pm}$ ) & & & 120 & $24 \%$ & 83 & $30 \%$ & 487 & $33 \%$ \\
\hline $\begin{array}{l}5 \mathrm{pm} \text { to Midnight } \\
(5 \mathrm{pm} \text { to } 11 \mathrm{pm})\end{array}$ & 18 & $19 \%$ & 182 & $37 \%$ & 98 & $35 \%$ & 325 & $22 \%$ \\
\hline Total & 93 & $99 \%$ & 486 & $98 \%$ & 281 & $96 \%$ & 1483 & $101 \%$ \\
\hline
\end{tabular}

*Time of adnission not recorded for 12 clients.

It would appear that the current researchers' conclusion that no clear pattern is discernible in ER usage is supported by the other studies cited here. However, neither of the other studies cross-tabulated time-of-day and day-of-week information as was done in the current study, so complete confirmation is lacking.

How Long Are Gients Spending in the ER?

Hersrud et al. do not present this type of information. As Table XI shows, data for the current study and the Talley study on clients admitted at UOHSC is fairly comparable. (Talley, Table 2, p. 22) 
TABLE XI

LENGTH OF STAY IN THE ER

\begin{tabular}{l|c|c|c|c}
\hline \multirow{2}{*}{ LENGTH OF STAY } & \multicolumn{2}{|c|}{ CURRENT STUDY } & \multicolumn{2}{c}{ TALLEY STUDY* } \\
\cline { 2 - 5 } & \multicolumn{2}{|c|}{ UOHSC } & $\%$ & \multicolumn{2}{|c}{ UOHSC } \\
\hline Less than 1 hour & 25 & $9 \%$ & 181 & $12 \%$ \\
1-2 hours & 96 & $33 \%$ & 325 & $22 \%$ \\
$2-4$ hours & 70 & $24 \%$ & 333 & $23 \%$ \\
More than 4 hrs & 10 & $: 3 \%$ & 128 & $9 \%$ \\
Unknown & 92 & $31 \%$ & 516 & $35 \%$ \\
\hline \multirow{2}{*}{ Total } & 293 & $100 \%$ & 1483 & $101 \%$
\end{tabular}

*Talley data categories were slightly telescoped to conform to data in the current study.

What Are Qients Receiving in the ER?

Treatment received. Talley presents no information on the treatment received by the patients in the study. Because the researchers in the current study and the Hersrud et al study were looking at their results from different perspectives, the final presentation of data in this category for the two studies is not comparable. Hersrud et al. were Interested in looking at the array of services available and how many c1ients were using them. Thus a client might be counted more than once if he or she received more than one service.

The researchers in the current study were interested in determining how marry of the clients admitted to the ER really needed the services of an ER (ie. medical treatment or hospitalization) and how many needed services that might have been better provided elsewhere. Here, the researchers looked at treatment as a continuum ranging from supportive therapy as 
the most superficial treatment provided, to agency referral, to medical treatment, to hospitalization as the most radical treatment provided. Thus, each client was categorized by the most radical treatment received. Hospitalizations. The data on the proportion of each study population that was hospitalized is very startling. For all four comparable populations or subpopulations, the proportions were virtually identical. See Table XII for the comparison. (Hersrud, Table XVIII, p. 172; Talley, Table 3, p. 23)

TABLE XII

PROPORTION OF STUDY POPULATIONS HOSPITALIZED

\begin{tabular}{|c|c|c|c|c|c|c|c|c|}
\hline & \multirow{2}{*}{\multicolumn{2}{|c|}{$\begin{array}{l}\text { HERSRUD STUD } \\
\text { GEN. HOSP'S }\end{array}$}} & \multicolumn{4}{|c|}{ CURRENT STUDY } & \multirow{2}{*}{\multicolumn{2}{|c|}{$\frac{\text { TALIEY STUDY }}{\text { UOHSC }}$}} \\
\hline & & & MUL & $\mathrm{co}_{\text {. }}$ & & & & \\
\hline & $\#$ & $\%$ & \pm & $\%$ & \# & $\%$ & $\#$ & $\%$ \\
\hline Hospitalized & 32 & $34 \%$ & 169 & $34 \%$ & 106 & $36 \%$ & 505 & $34 \%$ \\
\hline Not hosp'd & 61 & $66 \%$ & 329 & $66 \%$ & 187 & $64 \%$ & 980 & $66 \%$ \\
\hline Total & 93 & $100 \%$ & 498 & $100 \%$ & 293 & $100 \%$ & 1485 & $100 \%$ \\
\hline
\end{tabular}

Referrals. Talley reports that 366 patients (25\%) received referrals to services other than hospitals. (Table 3, p. 23) The current study found that 109 (38\%) of the UOHSC clients studied had been referred. The types of agencies to which clients were referred are listed in Table XIII.

Data reported by Hersrud et al. on how many clients were referred to other services is duplicative since some clients received more than one referral. They do, however, report that $32 \%$ of the clients seen in the general hospital ERs received no further service. (Tables LVI and IVII, p. 281) Comparable data from the Talley study shows $41 \%$ of all 
patients receiving no fur ther service. The current study reports $24 \%$ for the UOHSC portion of the study and $2.9 \%$ receiving no further services for all hospitals in Multnomah County.

TABLE XIII

TYPES OF AGENCIES TO WHICH

CLIENTS WERE REFERRED

\begin{tabular}{l|c|c|c|c}
\hline \multirow{2}{*}{$\begin{array}{l}\text { REFERRAL } \\
\text { AGENCIES }\end{array}$} & \multicolumn{2}{|c|}{ CURRENT STUDY } & \multicolumn{2}{c}{ TALLEY STUDY } \\
\cline { 2 - 5 } $\begin{array}{l}\text { Private } \\
\text { Physictan }\end{array}$ & 14 & $5 \%$ & 49 & \multicolumn{2}{c}{ UOHSC } \\
\hline $\begin{array}{l}\text { In-House Out- } \\
\text { Pt./Soc. Serv. }\end{array}$ & 27 & $9 \%$ & 216 & $15 \%$ \\
$\begin{array}{l}\text { Mental Heal th } \\
\text { Minic }\end{array}$ & 22 & $8 \%$ & 69 & $5 \%$ \\
$\begin{array}{l}\text { Private Social } \\
\text { Services }\end{array}$ & 20 & $7 \%$ & 13 & $1 \%$ \\
\hline $\begin{array}{l}\text { Substance Abuse } \\
\text { Services }\end{array}$ & 15 & $5 \%$ & 8 & NS \\
\hline $\begin{array}{l}\text { Other } \\
\text { Total }\end{array}$ & 11 & $4 \%$ & 11 & $1 \%$ \\
\hline
\end{tabular}

$\star N S=$ Not Significant

Court holds. Talley reports that 315 patients received treatment under the county contract for detainment on a notice of mental illness. This represents $21 \%$ of the study population. (Table 5, p. 26) Hersrud et al. found 14 clients (15\%) among the general hospital sample who were involuntary patients. (Table XV, p. 159) Nineteen percent of the UOHSC clients in the current study--a total of 56--were identified as police or physician court holds. There were no additional court holds at other Mul tnomah County hospitals so the percentage for the County sample falls to $11 \%$. 
What Brings These Giants to the ER?

Presenting problem and diagnosis. The current study attempted to differentiate between what the client saw as the reason for seeking help at an ER and what the actual problem was. The researchers felt this was a particularly unsuccessful endeavor. The reasons behind the lack of success are discussed el sewhere. The purpose of this effort was to analyze the possibility of redirecting those clients identified as questionable users to a service better suited (and less costly) to serve their needs. While the attempt was unproductive, the concept remains valid and a start has been made. Unfortunately, neither of the other studies appears to address this issue. Therefore only diagnoses will be compared here.

In examining the diagnostic categories used, the researcher found wide disparity between the studies. The diagnostic "art" is highiy controversial at best, and usually a matter of personal training and experience. The researcher is aware of the problems inherent in attempting to diagnose from second-hand information. The task of correlating diagnostic categories from one study to another is even more hazardous. Nevertheless, the researcher intends to do just that. Table XIIII shows the researcher's attempt at correlating the diagnostic categorles from the Talley and Hersrud studies with those used in the current study. (Hersrud, Table XVI, p. 161; Talley, Table 6, p. 29)

Based on this organization, data from all three studies was tabulated and compared. This comparison is presented in Table XIIV. 
TABLE XIIII

CORRELATION OF DIAGNOSTIC CATEGORIES

BETWEEN STUDIES

\begin{tabular}{|c|c|c|}
\hline CURRENT STUDY & TALIEY STUDY & HERSRUD STUDY \\
\hline Substance Abuse & $\begin{array}{l}\text { Overdose } \\
\text { Alcohol and Drug }\end{array}$ & $\begin{array}{l}\text { Alcohol/Drug Abuse } \\
\text { Suicide Attempt/Overdose }\end{array}$ \\
\hline Depression & $\begin{array}{l}\text { Suicide Attempt } \\
\text { Endogenous Depression } \\
\text { Reactive Depression } \\
\text { Manic-Depressive }\end{array}$ & \\
\hline Psychosis & $\begin{array}{l}\text { Schizophrenia } \\
\text { Psychosis }\end{array}$ & $\begin{array}{l}\text { Psychosis } \\
\text { Harassment }\end{array}$ \\
\hline $\begin{array}{l}\text { Transient Situational } \\
\text { Dis turbance }\end{array}$ & Emotionally Upset & $\begin{array}{l}\text { Transient Situational } \\
\text { Disturbance } \\
\text { Social/Marital } \\
\text { Maladjustment } \\
\text { Family Dispute }\end{array}$ \\
\hline Personality Disorder & Personality Disorder & Personality Disorder \\
\hline Neurosis & $\begin{array}{l}\text { Hysteria } \\
\text { Anxiety } \\
\text { Hyperventilation } \\
\text { Paranoia } \\
\text { Psychosomatic }\end{array}$ & Neurosis \\
\hline Medical & $\begin{array}{l}\text { Medical } \\
\text { Extrapyramidal Reaction }\end{array}$ & No mental disorder \\
\hline other & $\begin{array}{l}\text { Organic Brain Syndrome } \\
\text { Mental Retardation }\end{array}$ & $\begin{array}{l}\text { Organic Brain Syndrome } \\
\text { Other }\end{array}$ \\
\hline
\end{tabular}

Substance abuse is the most frequent diagnosis in the Hersrud study and in the Multnomah County portion of the current study; it ranks second in the UOHSC portion of the current study and third in the Talley study. Neurosis ranks second for Hersrud et al., and shared third ranking with substance abuse in the Talley study. It represents only a small proportion of the current study. Second in the Multnomah County portion of the curxent study is depression, a category not used in Hersrud's 
study; third ranking is held by psychosis. Psychosis ranks first in the UOHSC portion of the current study and second in the Talley study. The Talley study ranks depression first.

Substance abuse and psychosis rank in the top three for all four of the populations and subpopulations studies. Depression and neurosis rank in the top three for three of the samples.

\section{TABLE XIIV}

FREQUENCY OF DIAGNOSES

\begin{tabular}{|c|c|c|c|c|c|c|c|c|}
\hline & \multirow{2}{*}{\multicolumn{2}{|c|}{$\begin{array}{l}\text { HERSRUD STUDY } \\
\text { GEN. HOSP'S. }\end{array}$}} & \multicolumn{4}{|c|}{ CURRENT STUDY } & \multirow{2}{*}{\multicolumn{2}{|c|}{\begin{tabular}{|c|} 
TALIEY STUDY \\
UOHSC \\
\end{tabular}}} \\
\hline & & & \multicolumn{2}{|c|}{ MULT. $C 0$. } & \multicolumn{2}{|c|}{ UOHSC } & & \\
\hline & $\#$ & $\%$ & $\$$ & $\%$ & \# & $\%$ & $\#$ & $\%$ \\
\hline $\begin{array}{l}\text { Substance } \\
\text { Abuse }\end{array}$ & 30 & $32 \%$ & 135 & $27 \%$ & 65 & $22 \%$ & 227 & $15 \%$ \\
\hline Depression & $=$ & $\cdots$ & 100 & $20 \%$ & 61 & $21 \%$ & 349 & $23 \%$ \\
\hline Psychosis & 11 & $12 \%$ & 85 & $17 \%$ & 74 & $25 \%$ & 232 & $16 \%$ \\
\hline $\begin{array}{l}\text { Transient Sit. } \\
\text { Disturbance }\end{array}$ & 7 & $8 \%$ & 40 & $8 \%$ & 21 & $7 \%$ & 33 & $2 \%$ \\
\hline $\begin{array}{l}\text { Personality } \\
\text { Disorder }\end{array}$ & 2 & $2 \%$ & 30 & $6 \%$ & 26 & $9 \%$ & 180 & $12 \%$ \\
\hline Neurosis & 22 & $24 \%$ & 27 & $5 \%$ & 13 & $4 \%$ & 217 & $15 \%$ \\
\hline Medical & 3 & $3 \%$ & 27 & $5 \%$ & 7 & $2 \%$ & 102 & $7 \%$ \\
\hline Other & 11 & $12 \%$ & 54 & $11 \%$ & 26 & $9 \%$ & 48 & $3 \%$ \\
\hline Unknown & 7 & $8 \%$ & $=$ & $=$ & - & $=$ & 98 & $7 \%$ \\
\hline Total & 93 & ho1\% & 498 & $99 \%$ & 293 & $99 \%$ & 14886 & $100 \%$ \\
\hline
\end{tabular}

Transportation. Talley does not examine the need for or availability of transportation in the population. Hersrud et al. include transportation as an item to be ranked by agency personnel as part of the facility and as an aspect of coordination. Three respondents ranked the sufficiency of transportation to their facility as the most important 
positive aspect of the facility, and 27 others ranked it as the second or third most important positive aspect. On the other hand, 13 respondents identified the need for transportation to the facility as the most important area of the facility needing improvement; an additional thirtyseven respondents ranked it second or third in need for improvement. (The total possible number of respondents in the Hersrud et al. data on transportation is 101 . The actual response rate varies from 77 to 97.) (Table XXVIII, p. 192, and Table XXXII, p. 198)

Six respondents ranked the provision of transportation to a referfal agency as the most important positive aspect of coordination in their facility, and 13 others ranked it second or third. Conversely, 14 respondents ranked the need for transportation to the referral agency as the most important aspect of coordination needing improvement; 18 additional respondents ranked it second or third. (Table XXIX, p. 194, and Table XXXIII, p. 199)

The general conclusion which can be drawn from this data is that there is a perceived need for improvement in transportation to and from agencies and facilities which provide emergency psychiatric services. This corresponds to the opinions of service providers recorded by Multnomah County Mental Heal th Division officials in their informal surveys. In fact, the findings of the Hersrud et al. study, along with the data gathered by MOMHD officials, accounts for the inclusion of the questions on transportation in the current study.

It is interesting to note, therefore, that the current study does not support the need for improved or additional transportation. Thirtyeight percent of the UOHSC subpopulation in the current study needed 
transportation; 15 percent of the Multnomah County portion of the survey population needed transportation. Since these figures do not address the availability of transportation, however, standing alone they are somewhat deceptive and may explain why the perceived need was high. In order to determine what the actual need was, the researchers cross-tabulated the need for transportation with its availability.

The results contradicted the previous conclusions. Out of a total of 540 clients in the entire survey, only $25(5 \%)$ needed transportation when it was not available. For the UOHSC subpopulation, the percentage was slightly higher--7\%--and for the Multnomah County portion it was slightly lower--2\%. 


\section{CHAPTER IX}

\section{CONCLUSIONS AND RECOMMENDATIONS}

When the researchers began the current study, they hoped to have some questions answered when the study was completed. In reality, the study has raised more questions than it has answered. However, the questions point the way to an area of research with practical implications. It is hoped that this pilot study will encourage mental heal th researchers to delve more deeply into the issues addressed here. The local community provides especially abundant opportunity for further study.

\section{Conclusions}

Four broad conclusions can be drawn from the data presented here.

1. A considerable proportion of clients (perhaps as much as half) using the services of general hospital emergency rooms for emergency psychiatric care are medically indigent. The current study found that $58 \%$ of all clients in the study population had either no insurance coverage or were covered by other third-party payments besides insurance, such as Medicaid, SSI, etc. Talley found that only $13 \%$ of her study population had insurance or had incomes over $\$ 5,000$.

2. The number of psychiatric emergency clients being admitted to hospital ERs is substantial in relation to the total number of clients admitted. In addition, there is a need for mental heal th services beyond those currently provided by ERs. One means of dealing with this unnet need is to employ mental heal th professionals in the ER or to fa- 
miliarize current ER staff with community resource networks so that appropriate referrals to other services can be made. A longarange approach might involve a study of the feasibility of diverting emergency psychiatric clients to appropriate services before they reach the ER.

3. The actual need for transportation is not as great as the perceived need. It does not seem frivolous to conclude that if a client can get to the ER in the first place, he or she can usually get home or to another facility. This conclusion does not, however, address the needs of clients who never get to the ER. This issue deserves further definition and study.

4. There are no standardized record-keeping or data collection methods. This is true from hospital to hospital and from study to study. This problem is particularly noticeable in the areas of presenting problems and diagnoses. These inconsistencies make it difficult to compare information between hospitals and over periods of time, as well as from study to study. Talley and Hersrud et al. also found this to be a problem.

\section{Recommendation For Fur ther Study}

Al though all of the areas examined in this study deserve further study, particularly in regard to their implications for the mental heal th systems of the future, several issues were of particular interest to the researcher.

1. There is some indication that transients make up at least a small proportion of clients with mental heal th problems being admitted to hospital ERs. Is it relevant to focus on this segment of the population in future planning efforts? Does this population have needs not 
shared by other segments of the population? What are the implications of these needs in terms of future planning? Are there provisions in current mental heal th plans and services for the needs of this population? Are these provisions being implemented and maximized?

2. What is the impact of the medically indigent on emergency psychiatric services? The medically indigent have become an accepted, planned-for part of the health care system. Is this true of psychiatric services? Who pays for the psychiatric care of the medically indigent? Do they have access to tiee same range of services as those who can afford to pay for services? Is the emergency room becoming the "ghetto" of mental health services? Does the use of the emergency room as the "poor man's doctor" and "psychiatrist" have implications for the future of mental heal th services?

3. Neither the current study nor the Talley or Hersrud et al. studies found any clear, identifiable usage pattern with regard to the time of day or days of the week that clients are most likely to seed help for mental heal th problems. Are there, in reality, observable, identifiable usage patterns for mental heal th clients admitted to the ER? If patterns do exist, what generates them? Should an attempt be made to change them? What effect do they have on ER services? What are the implications of the possibility that no patterns exist?

4. Of what sigificance is the large proportion of emergency psychiatric clients between the ages of 21 and $35 ?$ Are the needs of these clients different from those of others? Are these differing needs, if any, addressed in current mental health services and plans? Should they be? 
5. Can diagnostic information be standardized and still be useful? Can diagnostic information be standardized at all? Do the disadvantages outweigh the advantages? Are there any correlations with diagnosis that might be useful in making predictions?

6. Is it feasible to divert clients with mental heal th problems, through the use of a modified "triage" service, to less costly, more appropriate services? What factors might be most useful in predicting which clients should be diverted? Are studies of "reasonable" vs. "questionable" users of ER services of any significance? Is it necessary to divert any of these clients? Are they having an impact on the delivery of traditional ER services? 


\section{EPILOGUE}

This study has covered a lot of ground, from the characteristics of the target population to a diagnosis of their mental heal th problems to a description of the services they received. It has made some assumptions and drawn some conclusions. It has answered a few questions and raised a few more.

This report has taken more than two years to produce, from its conception until now, as these final words are being written. While this study is ending, the research is really just beginning in the area of emergency psychiatric services. 


\section{REFERENCES}

Bergman, Anne Sturmthal. "Emergency Room: A Role for Social Workers." Heal th and Social Work 1 (February 1976): 32-44.

Blane, Howard T.; Muller, James J.; and Chafetz, Morris E. "Acute Psychiatric Services in the General Hospital: II. Current Status of Emergency Psychiatric Services." American Journal of Psychiatry 124 (1967): $37-45$.

Chafetz, Morris E.; Blane, Howard T.; and Muller, James J. "Acute Psychiatric Services in the General Hospital: I. Implications for Psychiatry in Emergency Admissions." American Journal of Psychiatry 123 (1966): 664-670.

Coleman, Jules V., and Errera, Paul. "The General Hospital Emergency Room and Its Psychiatric Problems." American Journal of Public Health 53 (August 1963): 1294-1301.

Hersrud, Maren L.; Kiser, Karalee; and Knox, Catherine M. "Psychiatric Emergency Services in Oregon." Master's Thesis, Portland State University, 1977.

Huffine, Carol L., and Craig, Thomas J. "Social Factors in the Utilization of an Urban Psychiatric Emergency Service." General Psychiatry 30 (February 1974): 249-255.

Parker, Anne K. "A Descriptive Study of Social Service Needs and Demographic Characteristics of Selected Emergency Roon Patients." Master's Practicum, Portland State University, 1978.

Talley, Sandra Lee. "Patients Use of Psychiatric Services in a University Hospital Emergency Room." Master's Thesis, University of Oregon School of Nursing, 1977. 
APPENDIX A

SURVEY FORM

DECEMBER 15, 1977 - JANUARY 15, 1978

EMERGENCY ROOM DATA

ON MENTAL HEALTH ADMISSIONS

(A) Hospital

(B) Date

(C) Time of ER Entry

(D) Discharge Time

(E) Age Ethnicity

(F) Sex

(G) Address

(H) Insurance Coverage? Yes Other 3rd Party Resource? Yes No No

(I) Why did the client come to the emergency room?

$(\mathrm{J})$ What was identified as the client's primary mental health problem?

(K) Who recommended that the client come to the ER? $\operatorname{Self}$ Agency Family Police Other: specify

(L) What treatment did the client receive in ER?

(M) Was the client hospitalized? Yes No If yes, where?

(N) Did you refer the client to another service? Yes No If yes, specify

(0) If not, to what kind of service would you like to have referred the client?

(P) Was transportation available (family, friends, police, ambulance, etc.)? Yes No

(Q) Was transportation available (family, friends, police, ambulance, etc.)? Yes No

(0) Were there any unresolved treatment problems or service needs? Yes No

If yes, please elaborate:

(S) Other comments: 
APPENDIX B

CATEGORIES USED TO

CLASSIFY RESPONSES

\section{A. HOSPITALS}

1. Dwyer Memorial Hospital

2. Eastmoreland General Hospital

3. Emanuel Hospital

4. Good Samaritan Hospital $\&$ Medical Center

5. Gresham Community Hospital

6. Holladay Park Hospital

7. Meridan Park Hospital

8. Physicians \& Surgeons Hospital

9. Portland Adventist Medical Center

10. Providence Medical Center

11. St. Vincent Hospital \& Medical Center

12. Sunnyside Medical Center

13. University of Oregon Health Sciences Center

14. Willamette Falls Community Hospital

15. Woodland Park Mental Health Center

\section{B. DAY OF WEEK}

1. Sunday

2. Monday

3. Tuesday

4. Wednesday

5. Thursday

6. Friday

7. Saturday

\section{TIME OF DAY}

1. $12: 01$ a.m. to $6: 00$ a.m.

2. $6: 01$ a.m. to Noon

3. $12: 01$ p.m. to $6: 00$ p.m.

4. 6:01 p.m. to Midnight

5. Unrecorded
D. LENGTH OF STAY

1. Less than one hour

2. One to two hours

3. Two to four hours

4. More than four hours

5. Unrecorded

E. AGE

1. $0-15$ years

2. 16-20 years

3. 21-35 years

4. 36-50 years

5. 51 years and older

6. Unrecorded

F. GENDER

1. Female

2. Male

3. Unrecorded

G. ADDRESS

1. North/Northeast

2. Southeast

3. West

4. East County

5. Clackamas County

6. Washington County

7. Outside Tri-County Area

8. Unrecorded

H. FINANCIAL RESOURCES

1. Insurance

2. Other third party

3. None

4. Unrecorded 


\section{PRESENTING PROBLEM}

1. Physical injuries

2. Physical complaints

3. Overdoses

4. Alcohol/Drug use effects

5. Suicide attempts/ Suicide ideation/ Suicide threats

6. Medication problems/ prescriptions \& refills/EPS

7. Depression/Anxiety/Nervousness/Sleeping Problems

8. Aggressive behavior

9. Abnormal/unusual behavior

10. Miscellaneous

\section{J. HOSPITAL DIAGNOSIS}

1. Neurosis

2. Character disorder

3. Substance abuse

a. Alcohol

b. Drug

4. Psychosis

5. Depression

6. Transient situational disturbance

7. Medical problems

8. Other

K. REFERRAL SOURCE

1. Self/family/friends

2. Agency

3. Police

4. Unknown

L. EMERGENCY ROOM TREATMENT

1. Assessment/diagnosis/supportive therapy

2. Assessment/diagnosis/agency referral

3. Assessment/diagnosis/medical attention

4. Assessment/diagnosis/

5. Other Psychiatric admission
M. HOSPITALIZED

1. No

2. Dammasch State Hospital

3. UOHSC

4. Woodland Park Mental Health Center

5. Holladay Park Hospital

6. Providence Medical Center

7. Portland Adventist Medical Center

8. Other hospital

9. Unknown

\section{N. REFERRAL}

1. No

2. Private physician

3. Private social services

4. County clinics

5. In-House Outpatient/Social

$$
\text { Services }
$$

6. Substance abuse service

7. Referring source

8. Dammasch State Hospital

9. Other hospital with psychiatric

10. Other unit

11. Unknown

O. SERVICES NEEDED

1. Immediate outpatient access

2. Residential care

3. Outreach/crisis intervention

4. Substance Abuse Services

5. Inpatient Psychiatric Admission

6. Locked secruity room

7. Not needed

8. Unknown/not ascertained

\section{P. TRANSPORTATION NEEDED}

1. Yes

2. No

3. Unrecorded 
APPENDIX B

Q. TRANSPORTATION AVAILABLE

1. Yes

2. No

3. Unrecorded

R. COURT HOLD

S. ADDITIONAL INFORMATION 


\section{APPENDIX C \\ RESPONSES IN WHICH CATEGORIZATION AND \\ INTERPRETATION WERE NECESSARY}

Address of Client

The address of clients living within Multnomah County were grouped according to mental heal th clinic quadrants since each quadrant represents a demographic service delivery system.

Why Did the Client Come to the ER?

It was anticipated that the responses to this question would reveal a distinction on the part of ER staff between a client with a primary medical problem with underlying mental heal th difficulties versus a client with a primary mental health problem. However, there was much evidence to indicate that many of the recorded responses reflected the clients' stated reason for coming to the ER rather than the ER staff's assessment of the primary problem.

Due to the differences in the kinds of responses to this question, it seemed advisable to look at this information in a more general way. than was originally intended. Responses to this question will be viewed as providing some broad indications of types of presenting problems.

Answers to the question "Why did the client come to the ER?" fell into nine broad categories, and one large miscellaneous category:

1. Physical injuries

2. Physical complaints
3. Drug/al cohol overdoses

4. Alcohol/drug use effects 
5. Suicide attempts/suicide ideation/suicide threats

6. Medication problems/EPS/ prescriptions and refills
7. Depression/anxiety/nervousness/ sleeping problems

8. Aggressive behavior

9. Abnormal/unusual behavior 10. Miscellaneous

Physical injuries include observable injuries from assault, automobile accidents, falls, and any other cause not specifically identified as self-inflicted. Physical complaints include headaches, toothaches, back pain, chest pain, etc. Drug/alcohol overdoses include only those cases so identified. No attempt is made to distinguish between deliberate and accidental overdoses. Alcohol/drug use effects do not include any identified overdoses; included in this category are intoxication and drug withdrawal. Suicide attempts/suicide ideation/suicide threats include all identified suicide-related problems except deliberate drug and al cohol overdoses.

Medication problems/extrapyramidal syndrome (EPS)/prescriptions and refills include requests for prescription drugs or refills, and symptoms identified as drug side-effects, as well as other, less specific problems with medications. Depression/anxiety/nervousness/sleeping problems is fairly self-explanatory. Aggressive behavior includes acts or threats of aggression towards others or towards property, but does not include dangerousness to self, which is included under suicide attempts/: ideation/threats.

Abnormal/unusual behavior covers all generally unusual behavior that does not come under another category, including, but not limited to, confusion, paranola, hallucinations, and agitation short of aggression. Miscellaneous, while the largest category when taken as a whole, actually contains many small groups of presenting problems including family and/or personal problems, seizures, returning for a prearranged appoint- 
ment, requesting to see a psychiatrist or requesting admission, needing a place to stay and other information and referral requests, and those brought in by the police with no presenting problem identified.

What Was Identified as the Gient's Primary Mental Heal th Problem?

The purpose of this question was to obtain the ER staff's diagnostic assessment of the client. Many responses were diagnostically imprecise; thus it was necessary to categorize the descriptive information given in accordance with the criteria set forth in the Diagnostic and and Statistical Manual (Second Edition).* The researchers recognize that this interpretative process may introduce a significant bias. The following diagnostic categories were most useful in reporting the recorded data:

Neurosis

Psychosis

Substance Abuse

Depression
Personality Disorder Transient Situational Disturbance Medical Problems other

Medical problems include clients whose presenting problem was identified as of a mental heal th nature, but which was attributable to medical causes, such as anxious disconfort due to EPS. It includes clients whose presenting problem was identified as medical, such as injury, but where there was a possibility of future mental heal th problems, such as in child abuse or wife abuse. It also included clients whose presenting problem and diagnosis were identified as medical in nature, but where a history of mental heal th problems, such as drug abuse, was present.

Other includes organic brain syndrome, identified wife or child 
abuse, other family problems, Dammasch State Hospital residents who were AMA or on trial visit and in need of transportation, and those clients for whom a diagnosis was not indicated. In most cases falling into this unrecorded-diagnosis category, the presenting problem involved the use of dtugs or alcohol. The researchers were hesitant, however, to include these clients in substance abuse in the absence of a specific diagnosis, al though a strong possibility exists that ER staff saw the primary mental heal th problem as identical to the presenting problem and so did not feel the necessity to answer the second question.

What Treatment Did the Qient Receive in the ER?

The reported data in response to this question was categorieed into four areas:

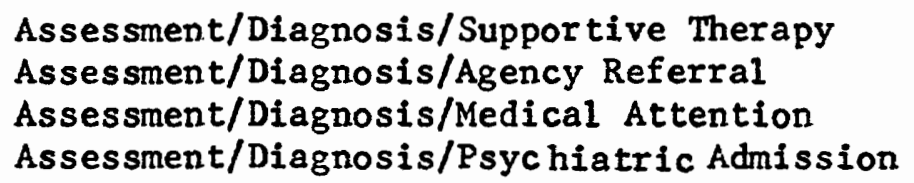

If the client was admitted to a psychiatric unit, the ER treatment was automatically categorized as assessment, diagnosis, and psychiatric admission. If the client was hospitalized in a medical unit or received medical treatment other than a prescription or refill (such as minor surgery, sutures, an I.V., etc.) the response was categorized as assessment, diagnosis, and medical attention.

If the completed questionnaire indicated that a client was not hospitalized and did not receive medical attention but was referred to an agency, the response was categorized as assessment, diagnosis, and agency referral. All remaining responses were categorized as assessment, diagnosis, and supportive therapy. 
This categorization suggests a behavioral description of ER usage-(a) clients presenting emergent problems necessitating medical attention or hospitalization, and (b) those with non-emergent problems in which supportive therapy was rendered or an agency referral made. These two usage patterns are discussed in the Major Findings.

To What Service Would the Emergency Room Staff Like to Have Referred the Cient? Were There Any Unresolved Treatment Problems or Other Services Needed?

The purpose of these two questions was to identify community mental health service gaps. The specific responses to both questions were recorded as one, since they address the same issue. When the questions were not answered, but the client was hospitalized, it was assumed that no other service was needed since some disposition had been made.

\section{Court Holds}

Although a specific question was not asked regarding court holds, these cases (police and physician holds) were generally indicated on the returned questionnaire. If a few cases the court hold was assumed to have been in effect since peace officer transport to the state hospital occurred. This assumption seems reasonable since police do not provide transportation to the state hospital except in such instances. 